\title{
Kilometer-scale structure on the core-mantle boundary at the source of the Hawaiian mantle plume
}

\section{Zhi Li ( $\boldsymbol{D}_{\text {zl382@cam.ac.uk) }}$}

University of Cambridge https://orcid.org/0000-0001-5657-655X

\section{Kuangdai Leng}

Rutherford Appleton Laboratory

Jennifer Jenkins

University of Cambridge

\section{Sanne Cottaar}

Cambridge University

Physical Sciences - Article

Keywords: core-mantle boundary, Hawaiian mantle plume

Posted Date: January 12th, 2021

DOI: https://doi.org/10.21203/rs.3.rs-118686/v1

License: (9) This work is licensed under a Creative Commons Attribution 4.0 International License. Read Full License 


\title{
Title: Kilometer-scale structure on the core-mantle boundary at the source of the Hawaiian mantle plume
}

\author{
Authors: Zhi Li ${ }^{1 *}$, Kuangdai Leng ${ }^{2,3}$, Jennifer Jenkins ${ }^{1}$, Sanne Cottaar ${ }^{1}$.
}

\section{Affiliations:}

1Bullard Laboratory, Department of Earth Sciences, University of Cambridge, CB3 0EZ, UK.

2Department of Earth Science, University of Oxford, OX1 3AN, UK.

${ }^{3}$ Rutherford Appleton Laboratory, Science and Technology Facilities Council, Didcot OX11 OQX, UK.

${ }^{*}$ Correspondence to: zl382@cam.ac.uk.

\begin{abstract}
The lowermost mantle right above the core-mantle boundary shows a complex and heterogeneous landscape containing multiple poorly understood seismic features visible across a 15 wide range of length scales. The smallest, but most extreme, heterogeneities yet observed are 'Ultra-Low Velocity Zones' (ULVZ), several of which have recently been linked to the base of mantle plumes. We exploit seismic shear waves that diffract along the core-mantle boundary to provide new insight into these enigmatic structures. We demonstrate that these waves have a strong frequency-dependent sensitivity to structure at different length scales above the core-

20 mantle boundary, similar to the dispersive characteristics of surface waves. We measure a rare core-diffracted signal refracted by a ULVZ at the base of the Hawaiian mantle plume at unprecedented high frequencies. This signal shows remarkably longer time delays compared to lower frequencies, indicating extreme internal variability within the Hawaiian ULVZ. Utilizing the latest computational advances in 3D synthetic waveform modeling, we are able to model this

25 high frequency signal and constrain high-resolution structure on the scale of kilometers at the core-mantle boundary, for the first time. Results reveal that the lowermost part of the Hawaiian ULVZ is extremely reduced in shear wave velocity, by up to $-40 \%$. This new observation suggests a chemically distinct ULVZ with increasing iron content towards the core-mantle boundary, which has implications for Earth's early evolutionary history and core-mantle
\end{abstract}

30 interaction.

\section{Introduction}

The core-mantle boundary separates the Earth's liquid iron-nickel outer core from the solid silicate mantle. Heat from the core powers convection in the mantle, driving hot buoyant upwellings known as mantle plumes, that rise from the core-mantle boundary to the Earth's surface where they form hotspots and volcanoes. Over the past few decades, seismology has revealed that the landscape of the core-mantle boundary is highly heterogeneous, potentially analogous to the level of variability seen on the Earth's surface. 
Ultra-Low Velocity Zones (ULVZs) represent the most extreme core-mantle boundary features yet observed, generally showing shear-wave velocity reductions of $10 \%$ to $30 \%{ }^{1}$. However, the small height of these structures - only tens of kilometers thick - means they are below the resolution limit of tomographic models, requiring higher frequency seismic waves to image them. Currently available seismic data has limited geometries that can be used to image these structures and therefore only a fraction of the core-mantle boundary is illuminated. Despite this, a number of ULVZs varying in size, shape and velocity reduction have been reported ${ }^{1}$. Early studies interpreted ULVZs as sporadic and localized structure, but had little constraint on their lateral extent ${ }^{2-4}$. More recently four unusually large ULVZs linked to areas of hotspot volcanism have been mapped near Hawaii ${ }^{5}$, Iceland ${ }^{6}$, Samoa $^{7}$ and the Marquesas ${ }^{8}$. Unlike earlier studies, which suggested ULVZs represented small-scale structures, these new observations indicate the presence of thin but wide ULVZs, on the order of 600-900 km across. These have been dubbed 'mega-ULVZs' in some literature. The large aspect ratio of mega-ULVZs suggest they are very dense compared to their surroundings ${ }^{9}$, which could be explained by iron enrichment ${ }^{10,11}$. Increasing evidence suggests that the correlation between the geographic location of megaULVZs and surface hotspots may not be a coincidence, i.e. the isotopic tungsten anomalies collected in hotspot lavas indicate a primordial material or a core-signature in the mantle plume $^{12}$.

Three of the recently observed mega-ULVZs, beneath Hawaii, Iceland and the Marquesas, have been discovered using core diffracted shear-waves known as $\mathbf{S}_{\text {diff }}{ }^{5,6}$. $S_{\text {diff }}$ phases are observed at epicentral distances over $100^{\circ}$ from the earthquake epicenter, sometimes extending to up $140^{\circ}$ after a long refraction path along the core-mantle boundary (Fig. 1B). Higher frequency $\mathrm{S}_{\text {diff }}$ energy gets trapped in thin mega-ULVZs, becoming delayed and refracted. On a seismogram these guided waves appear tens of seconds after the main $S_{\text {diff }}$ phase, and for a cylindrical ULVZ show a hyperbolic delayed move-out as a function of azimuth ${ }^{5}$. We refer to these as $\mathrm{S}_{\text {diff }}$ postcursors. The travel time delays of $S_{\text {diff }}$ postcursors hold information on the size, shape, and average velocity reduction of the ULVZ they sample ${ }^{5}$. Here we demonstrate that the frequency content and dispersive properties of these phases also contain information on the vertical internal velocity structure of ULVZs. Although $\mathrm{S}_{\text {diff }}$ waves sample a reasonably large area of the core-

70 mantle boundary, the observation of $S_{\text {diff }}$ postcursor waves is still very rare. This is partly due to the requirement of a continuous and dense array of recording seismic stations. The previous observations of mega-ULVZs can all be attributed to the deployment of the large-scale US Transportable Array ${ }^{13}$.

\section{Location of the Hawaiian ULVZ}

When $\mathrm{S}_{\text {diff }}$ postcursors illuminate a ULVZ from a specific direction, determining its exact location has a degree of freedom along the diffracted path, and there are trade-offs between location, size, and velocity reduction in the modelling of these structures. The Hawaiian ULVZ was initially identified using $S_{\text {diff }}$ waves from deep earthquakes in Papua New Guinea recorded 80 at the transportable array and other stations in the central United States ${ }^{5}$ (Fig. S2). This left uncertainty as to the exact location of the ULVZ in the NE-SW direction along the $\mathrm{S}_{\text {diff }}$ path, and calls into question the reliability of the simplified cylindrical model proposed to fit the data. With the redeployment of the transportable array to Alaska starting in 2014, increased data coverage of $\mathrm{S}_{\text {diff }}$ waves that highlight the Hawaiian ULVZ in the N-S direction is now available. Five 
deep earthquakes from the Kermadec trench recorded in Alaska show postcursor energy caused by the Hawaiian ULVZ (Fig S3). Using this new data, we are now able to pinpoint the precise location of the Hawaiian ULVZ with unprecedented accuracy (Fig. 1A). The hyperbolic travel times of postcursors across this data set suggest the ULVZ is centered at $172.3^{\circ} \mathrm{W}$ and $15.4^{\circ} \mathrm{N}$ offset further southwest from the Hawaiian Islands than previously thought ${ }^{5}$. Synthetic modelling of the waveforms from two directions indicate a highly axisymmetric cylindrical shape to the ULVZ (Fig. S2 and S3), similar to that proposed for the Icelandic ULVZ6.

\section{High-frequency $S_{\text {diff }}$ Postcursors}

Previously, $S_{\text {diff }}$ postcursors have been observed down to periods of 10 s (frequencies $\leq 0.1 \mathrm{~Hz}$ ), which limits the vertical resolution of imaged ULVZs to tens of kilometers (Fig. 1C). This is insufficient to unravel the details of internal ULVZ velocity gradients, which requires the exploitation of higher-frequency observations. However, pushing $\mathrm{S}_{\text {diff }}$ observations to higher frequencies is challenging: arrival amplitudes are weaker, background noise from ocean waves is louder (peaking at $0.14 \mathrm{~Hz}$ ), and the computational costs for modeling full 3D synthetic data increases exponentially with frequency ${ }^{14,15}$. In this study, we make the first high-frequency observations of $\mathrm{S}_{\text {diff }}$ postcursors down to $3 \mathrm{~s}(\leq 0.3 \mathrm{~Hz})$, allowing us to infer internal ULVZ structure on the order of kilometers.

We focus on the high-quality $S_{\text {diff }}$ data from a 2010 earthquake in the Papua New-Guinea area recorded in the contiguous United States (Fig. 1A in yellow). The $S_{\text {diff }}$ observations are filtered into two frequency bands for comparison, one from 10 to $20 \mathrm{~s}$ ('long-period'), and one from 3 to $6 \mathrm{~s}$ ('short-period'). The energy of the short-period phase is very weak; it is barely observable in the raw data (Fig. S1). To enhance the signal-to-noise ratio, we apply a sub-array phase-weighted beamforming technique for each station and its nearest 20 neighbors (Materials and Methods), which stacks the signals based on phase and directional coherency. Figure 2 shows the results of this phase-weighted stacking in separate time windows for the main $\mathrm{S}_{\text {diff }}$ arrivals and postcursors, each stacked along their respective incoming directions (Fig. 2C and 2F). The long-period $\mathrm{S}_{\text {diff }}$ stacked signals (Fig. 2A) look similar to unstacked waveforms (Fig. S1), while the short-period postcursor stacked signals (Fig. 2D) emerge from what appears to be only background noise in the raw data (Fig. S1).

115 We observe that at long-periods the postcursor arrives at around 35 to 50s, varying with azimuth (Fig. 2B). Strikingly, at short-periods the postcursors are significantly more delayed, arriving at 50 to 70 s (Fig. 2E). Frequency dependent travel times with differences on the order of tens of seconds between long and short-period $\mathrm{S}_{\text {diff }}$ postcursor waves has never before been documented, though a weak frequency-dependent dispersion of core-diffracted waves has been suggested based on global statistical analysis of ray parameters ${ }^{16}$. The main $\mathrm{S}_{\text {diff }}$ phase and the postcursor have different incoming directions (Fig. S5) due to 3D out-of-path effects. While the incoming backazimuth direction of $\mathrm{S}_{\text {diff }}$ phases are slightly scattered (Fig. $2 \mathrm{C}$ and $2 \mathrm{~F}$ ), they remain reasonably consistent across both long- and short-period measurements. Gradual deviation from $0^{\circ}$ to $15^{\circ}$ away from the epicenter backazimuth (Fig. $2 \mathrm{C}$ and $2 \mathrm{~F}$ ) implies a strong 125 bending effect that can only be explained by interaction with a structure of strong velocity contrast (5). Combining observations of postcursor travel time delays and backazimuth deviations, suggests that while waves at the two periods sample similar geographical regions, the 
seismic velocities at the different length scales above the core-mantle boundary they are sensitive to, differ significantly.

\section{Modeling of the ULVZ Basal Layer}

Detailed waveform modelling of the Hawaiian ULVZ based on long-period postcursor data has been shown in (5). We refine their preferred model of a $20 \mathrm{~km}$ tall cylindrical ULVZ of radius $455 \mathrm{~km}$ with velocity reduction of $20 \% \mathrm{Vs}$, to include details of finer internal structure based on our short-period observations and updated location. Initially we explore the model space of a simplified cylindrical ULVZ using computational-cheap ray-based modelling (Fig. S9, S10), followed by $2.5 \mathrm{D}$ modelling ${ }^{15}$ down to $3 \mathrm{~s}$ (Materials and Methods). This reveals that the shortperiod postcursor observations can be explained by an $\sim 2 \mathrm{~km}$ thick layer with extreme velocity reduction $(-40 \% \mathrm{Vs})$ at the base of the ULVZ, or by the presence of a less anomalous, but wider

140 spread, basal-layer (Fig. S11).

While it is still very challenging to simulate full 3D ULVZ synthetics at the high frequencies we explore here, a recent method development combining wavefield injection with AxiSEM3D makes full 3D global ULVZ synthetics down to 1 s achievable for the first time ${ }^{17}$. We compute

$1453 \mathrm{D}$ synthetics using a $20 \mathrm{~km}$ thick ULVZ model with an extreme $2 \mathrm{~km}$ basal layer of $-40 \% \mathrm{dVs}$ based on our 2.5D modeling, as well as three additional models for comparison (Fig. 3C): a uniform ULVZ of $-20 \% d V_{S}$, a gradient ULVZ varying from $-10 \% d V_{S}$ at the top to $-30 \% d V_{S}$ at the bottom, and a two-layered ULVZ with an upper $10 \mathrm{~km}$ at $-10 \% \mathrm{dV}$ and a bottom $10 \mathrm{~km}$ at $30 \% \mathrm{dV}_{\mathrm{S}}$ (Fig. 3C). The latter three models have an equivalent velocity reduction when

150 integrated vertically across the ULVZ. Broadband (Fig. 3B) and long-period data (Fig. S12A) are unable to discriminate between these four models. Short-period data however, show strong differences in the travel times of the modeled $\mathrm{S}_{\text {diff }}$ postcursors (Fig. 3A), with the uniform ULVZ model showing the weakest delay times and the two-layered model showing the strongest delay times. Both the gradient ULVZ and the ULVZ with a $2 \mathrm{~km}$ extreme basal layer show good fits to

155 the observed dispersion across both frequency bands. While not presenting a unique solution, these 3D high-frequency synthetics do demonstrate that we have the ability to resolve a kilometer-scale basal-layer structure at the core-mantle boundary, and that strong velocity layering or gradients explains the observed dispersion.

\section{Implications for Earth's early evolution history and core-mantle interaction}

This unprecedented record of extreme seismic velocity reduction in the basal-layer of the Hawaiian mega-ULVZ sheds new light on the nature of these features and the complex processes happening at the core-mantle boundary. The steep thermal boundary just above the core is likely to explain some of the change in velocity with depth, but thermal effects can, at most, only 165 explain several percent velocity reduction. The axisymmetric shape of the ULVZ suggests a natural dynamical link between a cylindrical plume upwelling and the partial melting that might occur at its base ${ }^{6}$. However, the extreme shear velocity reductions of up to $40 \%$ that we observe would require a melt fraction likely above the percolation threshold ${ }^{18}$. Additionally, these melts are likely to be iron-rich and denser than the solid ${ }^{19}$, causing melts to drain out ${ }^{18}$. 
Our velocity constraints instead suggest a compositionally distinct mega-ULVZ containing increasing iron content with depth. Iron-rich post-perovskite ${ }^{20}$ or iron-rich magnesiowüstite ${ }^{11}$ have been proposed as candidate minerals that could form significant proportions of solid-state ULVZs. Mixing iron-rich magnesiowüstite with bridgmenite would suggest a model with $\sim 15 \%$ magnesiowüstite at the top to $\sim 80 \%$ magnesiowüstite at the base ${ }^{11}$. Strongly iron-enriched compositions in the lowermost mantle may trace Earth's early impact history, when iron-rich impactor cores mixed with the silicate mantle and accumulated at the core-mantle boundary ${ }^{21}$. Alternatively, the material represents a remnant of an ancient global basal magma ocean ${ }^{22}$. In this case, the vertical varying ULVZ structure might holds clues to changing levels of iron

180 fractionation at different stages of magma ocean crystallisation.

An alternative source of iron enrichment in the lowermost mantle is through interactions with the Earth's core. The more diffuse velocity transition beneath mega-ULVZs might serve as a unique source area of mass transfer from the core. This is supported by observations of anomalous,

185 potentially core-related, isotopic signals in hotspot lavas ${ }^{12,24,25}$, which imply the Hawaiian ULVZ is not a closed reservoir, but is likely to be entrained in small amounts into the plume ${ }^{26}$. Our observation also seems to fit the proposed manifestations of hydrous minerals. In this scenario the vertically varying structure of the ULVZ might represent a chemical gradient zone, where a reaction series between water and iron is happening ${ }^{27}$.

\section{References}

1. Yu, S. \& Garnero, E. J. Ultralow Velocity Zone Locations: A Global Assessment. Geochemistry, Geophys. Geosystems 19, 396-414 (2018).

2. Garnero, E. J. Heterogeneity of the lowermost mantle. Annu. Rev. Earth Planet. Sci. 28, 509-537 (2000).

3. Garnero, E. J., Revenaugh, J., Williams, Q., Lay, T. \& Kellogg, L. H. Ultralow velocity zone at the core-mantle boundary. in The Core-Mantle Boundary Region (eds. Gurnis, M., Wysession, M. E., Knittle, E. \& Buffett, B. A.) vol. 28 319-334 (American Geophysical Union, 1998).

4. Thorne, M. S. \& Garnero, E. J. Inferences on ultralow-velocity zone structure from a global analysis of SPdKS waves. J. Geophys. Res. Solid Earth 109, (2004).

5. Cottaar, S. \& Romanowicz, B. An unsually large ULVZ at the base of the mantle near Hawaii. Earth Planet. Sci. Lett. 355-356, 213-222 (2012).

6. Yuan, K. \& Romanowicz, B. Seismic evidence for partial melting at the root of major hot spot plumes. Science (80-. ). 357, (2017).

7. Thorne, M. S., Garnero, E. J., Jahnke, G., Igel, H. \& McNamara, A. K. Mega ultra low velocity zone and mantle flow. Earth Planet. Sci. Lett. 364, 59-67 (2013).

8. Kim, D., Lekić, V., Ménard, B., Baron, D. \& Taghizadeh-Popp, M. Sequencing seismograms: A panoptic view of scattering in the core-mantle boundary region. Science (80-. ). 368, 1223-1228 (2020).

9. Bower, D. J., Wicks, J. K., Gurnis, M. \& Jackson, J. M. A geodynamic and mineral 
physics model of a solid-state ultralow-velocity zone. Earth Planet. Sci. Lett. 303, 193202 (2011).

10. Wicks, J. K., Jackson, J. M. \& Sturhahn, W. Very low sound velocities in iron-rich

12. Mundl, A. et al. Tungsten-182 heterogeneity in modern ocean island basalts. Science (80.). 356, 66-69 (2017).

13. IRIS Transportable Array. USArray Transportable Array. (2003) doi:10.7914/SN/TA.

14. Nissen-Meyer, T. et al. AxiSEM: Broadband 3-D seismic wavefields in axisymmetric media. Solid Earth 5, 425-445 (2014).

15. Leng, K., Nissen-Meyer, T., Van Driel, M., Hosseini, K. \& Al-Attar, D. AxiSEM3D: Broad-band seismic wavefields in 3-D global earth models with undulating discontinuities. Geophys. J. Int. 217, 2125-2146 (2019).

16. Euler, G. G. \& Wysession, M. E. Geographic variations in lowermost mantle structure from the ray parameters and decay constants of core-diffracted waves. J. Geophys. Res. Solid Earth 122, 5369-5394 (2017).

17. Leng, K., Korenaga, J. \& Nissen-Meyer, T. 3-D scattering of elastic waves by small-scale heterogeneities in the Earth's mantle. Geophys. J. Int. 223, 502-525 (2020).

18. Hernlund, J. W. \& Jellinek, A. M. Dynamics and structure of a stirred partially molten ultralow-velocity zone. Earth Planet. Sci. Lett. 296, 1-8 (2010).

19. Nomura, R. et al. Spin crossover and iron-rich silicate melt in the Earth's deep mantle. Nature 473, 199-202 (2011).

20. Mao, W. L. et al. Iron-rich post-perovskite and the origin of ultralow-velocity zones. Science (80-. ). 312, 564-565 (2006).

21. Jackson, C. R. M., Bennett, N. R., Du, Z., Cottrell, E. \& Fei, Y. Early episodes of highpressure core formation preserved in plume mantle. Nature 553, 491-495 (2018).

22. Labrosse, S., Hernlund, J. W. \& Coltice, N. A crystallizing dense magma ocean at the base of the Earth's mantle. Nature 450, 866-869 (2007).

23. Li, M., McNamara, A. K., Garnero, E. J. \& Yu, S. Compositionally-distinct ultra-low velocity zones on Earth's core-mantle boundary. Nat. Commun. 8, (2017).

245 24. Brandon, A. D. \& Walker, R. J. The debate over core-mantle interaction. Earth Planet. Sci. Lett. 232, 211-225 (2005).

25. Mundl-Petermeier, A. et al. Anomalous $182 \mathrm{~W}$ in high $3 \mathrm{He} / 4 \mathrm{He}$ ocean island basalts: Fingerprints of Earth's core? Geochim. Cosmochim. Acta 271, 194-211 (2020).

26. Jones, T. D., Davies, D. R. \& Sossi, P. A. Tungsten isotopes in mantle plumes: Heads it's positive, tails it's negative. Earth Planet. Sci. Lett. 506, 255-267 (2019). 
27. Mao, H. K. et al. When water meets iron at Earth's core-mantle boundary. Natl. Sci. Rev. 4, 870-878 (2017).

28. French, S. W. \& Romanowicz, B. A. Whole-mantle radially anisotropic shear velocity structure from spectral-element waveform tomography. Geophys. J. Int. 199, 1303-1327 (2014).

260 Acknowledgments We acknowledge the IRIS (Incorporated Research Institutions for Seismology) data center for providing all the data. This work was performed using resources provided by the Cambridge Service for Data Driven Discovery (CSD3) operated by the University of Cambridge Research Computing Service. We thank D. AlAttar for input on the kernel calculation and W. Liu for discussions on our interpretation.

265 This work is supported by the European Research Council (ERC) under the European Union's Horizon 2020 research and innovation programme (grant agreement No.804071-ZoomDeep). K.L is supported by US-NSF and UK-NERC under joint grant NE/R012199/1 and by US-NSF under grant EAR-1610612.

Author contributions Z.L.: Conceptualization, Methodology, Software, Formal 270 Analysis, Writing - Original Draft, K.L.: Methodology, Software. J.J.: Visualization, Writing- Review \& Editing, Supervision. S.C. Conceptualization, Methodology, WritingReview \& Editing, Supervision, Funding acquisition.

Competing interests Authors declare no competing interests. 

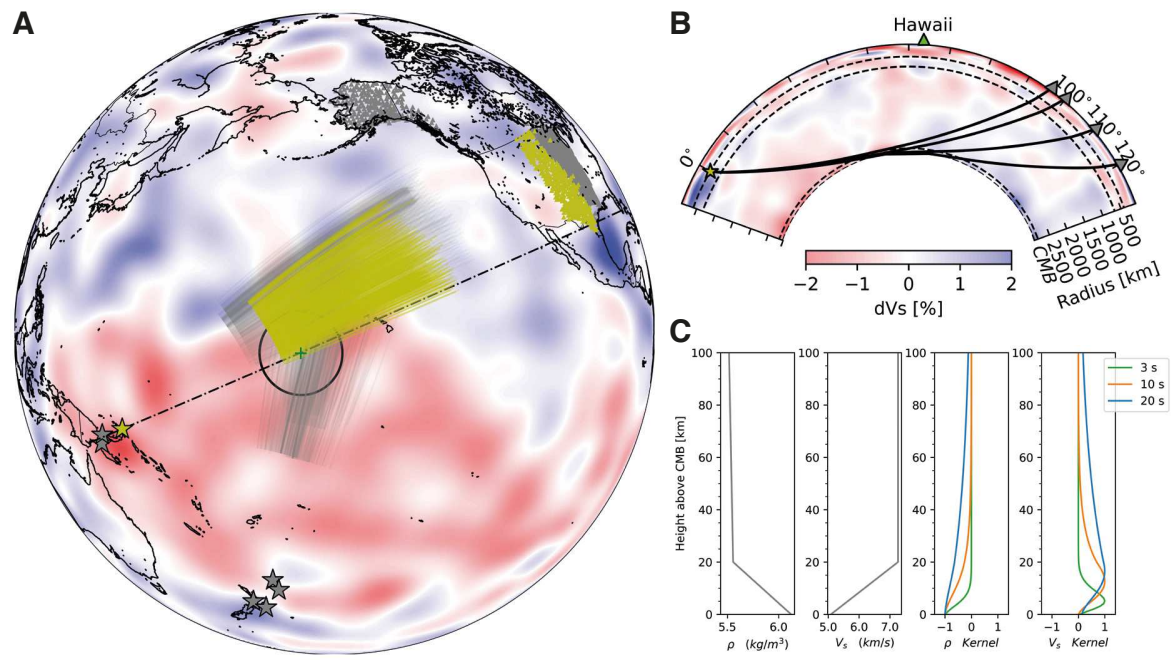

Fig. 1. S Siff ray paths and sensitivity to velocity structure. (A) Events (stars), stations (triangles), and raypaths of $S_{\text {diff }}$ waves in the lowermost mantle used in this study, the event used in short-period analysis highlighted in yellow. Proposed ULVZ location shown with black circle. Background shows tomography model SEMUCB_WM1 at $2800 \mathrm{~km}$ depth $^{28}$. (B) Cross section 290 along the black dashed line in (A) slicing the center of Hawaiian ULVZ, showing raypaths of $\mathrm{S}_{\text {diff }}$ waves at $96^{\circ}, 100^{\circ}, 110^{\circ}$ and $120^{\circ}$. (C) Estimated sensitivity kernels of $\mathrm{S}_{\text {diff }}$ waves for a model containing strongly reduced velocities at the core-mantle boundary. From left to right: density profile, shear wave velocity profile, density kernel, and shear wave kernel for $S_{\text {diff }}$ waves at period of $3 \mathrm{~s}, 10 \mathrm{~s}$ and $30 \mathrm{~s}$. 

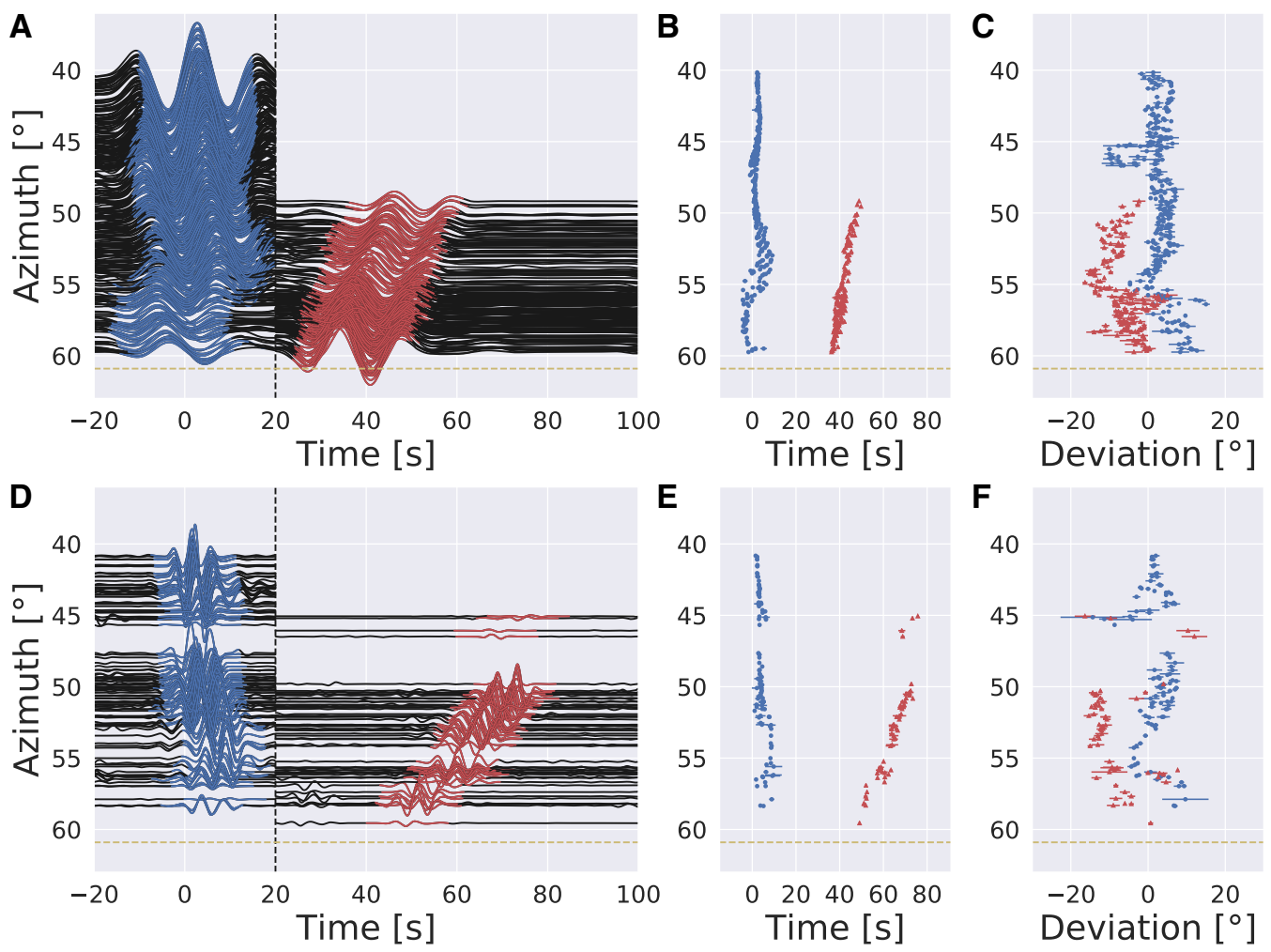

Fig. 2. Stacked data and beamforming results for the main $S_{\text {diff }}$ phases and postcursors arrivals. (A) Phase weighted stacks for 10-20s filtered data. Data stacks before 20s (black dashed line) use the incoming direction of the main arrival (blue), post 20s stacks use the incoming direction of postcursor energy (red). (B) Travel time measurements from the maxima of stacked waveform envelopes in A. (C) Backazimuth deviations, i.e. the incoming directions used in the stacks. Error bars represent the max variance of the measurement when the value of $\mathrm{S}_{\text {diff }}$ slowness is varied by $\pm 5 \%$. (D-F) as for A-C but for 3-6s filtered data. Yellow dashed lines show the azimuth through the center of the proposed ULVZ 

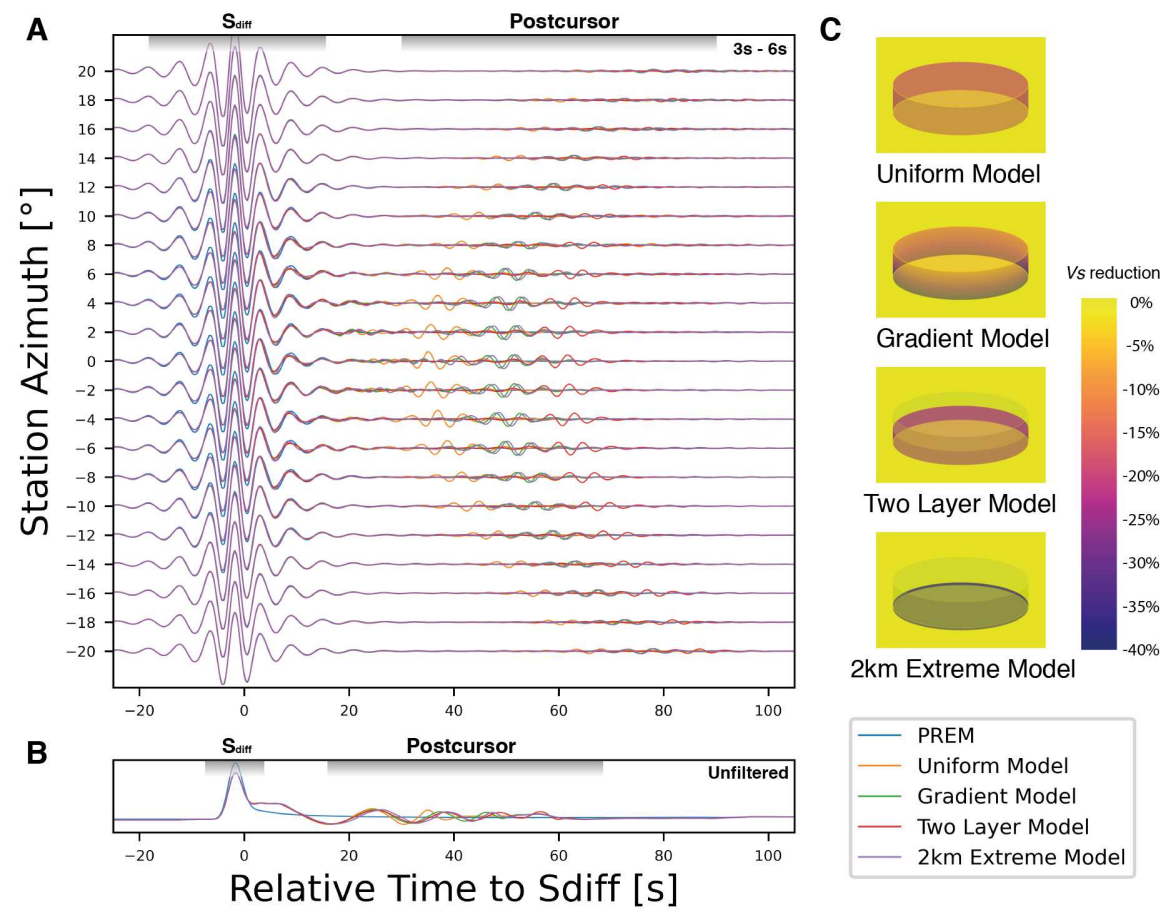

Fig. 3. Synthetic global wavefield of four 3D ULVZ models computed to 3s periods. (A)

310 Synthetic waveforms at an epicentral distance of $105^{\circ}$, filtered between $3 \mathrm{~s}-6 \mathrm{~s}$ periods, displayed as a function of azimuth relative to the ULVZ center. (B) Synthetic waveform including all period content down to $3 \mathrm{~s}$ period at $0^{\circ}$ relative station azimuth. (C) Illustration of the four different ULVZ models. 

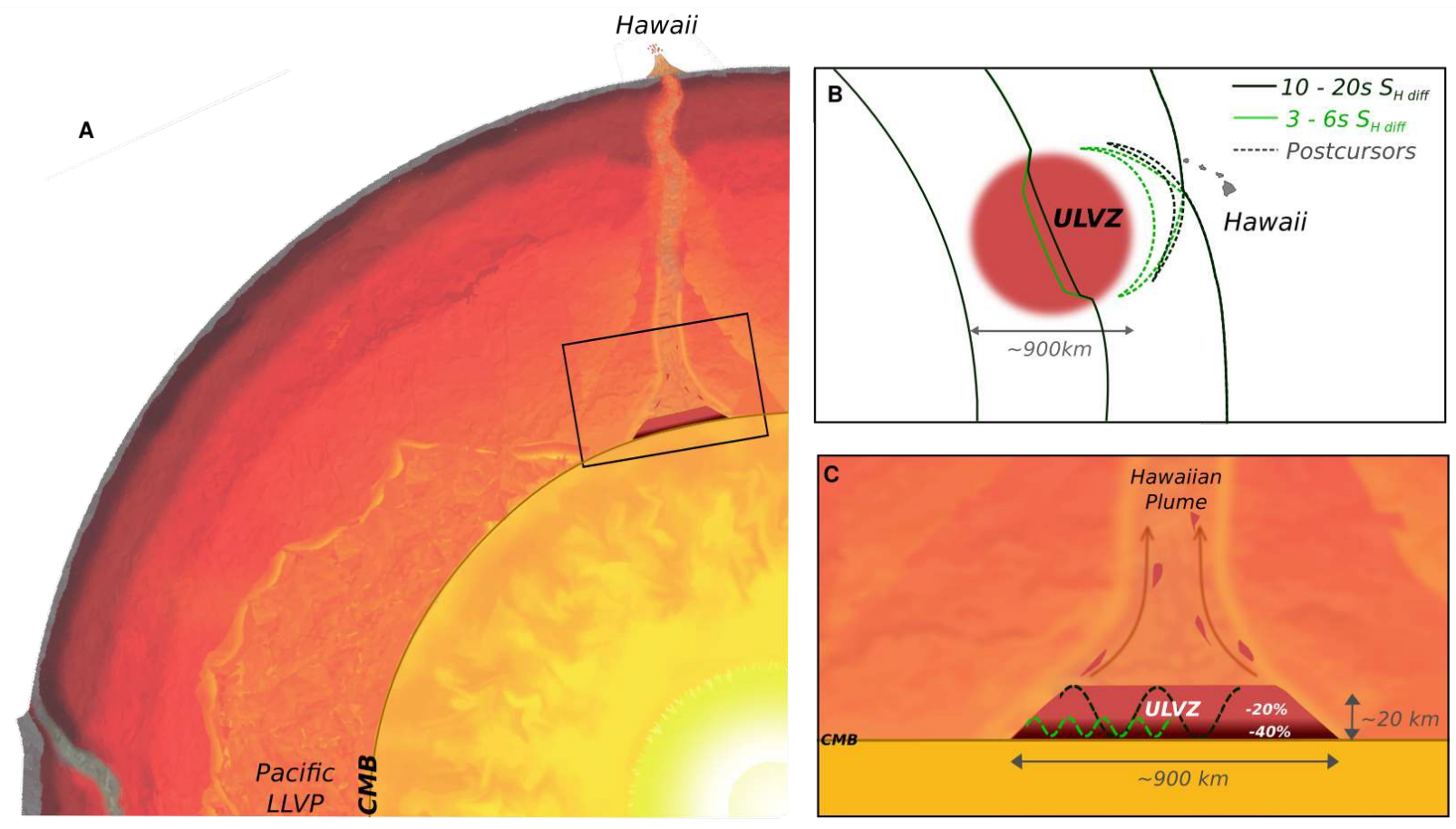

Fig. 4. Conceptual cartoons of the Hawaiian ULVZ. (A) ULVZ on the core-mantle boundary at the base of the Hawaiian plume (height is not to scale), (B) sketch of wavefront refraction for the long-period (black) and short-period (green) $S_{\text {diff }}$ postcursors, and (C) a zoom in of modeled ULVZ structure, showing interpreted trapped postcursor waves (note that the waves analysed 325 have horizontal displacement). 


\section{Methods}

\section{Data Processing}

All the data for this study is obtained from the IRIS Data Management Center. We select eight events with depths from 12 to $413 \mathrm{~km}$ and seismic moment magnitude from 5.9 to 7.8 that sample the Hawaiian ULVZ. The detailed source information is shown in the Table S1. We remove the instrument response by convolving the original data with the inverted instrument spectrum using ObsPy ${ }^{1}$. Horizontal components are rotated to the radial and tangential orientations. In this study we analyze the tangential component of the seismogram, because the SH component of the $\mathrm{S}_{\text {diff }}$ wave propagates further and attenuates less than the SV component and thus has stronger energy. Low-quality noisy traces are manually identified and removed. We use a zero-phase fourth-order Butterworth band-pass filter for filtering. Examples of the tangential component $\mathrm{S}_{\text {diff }}$ data for the 2010 event filtered in 10-20s and 3-6s period bands and presented as a function of azimuth are shown in Fig. S1.

\section{Update on Location of Hawaiian ULVZ}

The previous modeled location of show Hawaiian ULVZ sits just southwest of the surface hotspot, centered roughly between $172.5 \mathrm{~W}$ and $162.5 \mathrm{~W}^{2}$. With the diffracted data from events in Papua New Guinea recorded at the transportable array in the central USA, which propagate mainly from west to east, the ULVZ location was well constrained latitudinally (Fig. S2), but a degree of uncertainty remained as to the exact longitudinal location due to lack of crossing data at the time of publication. The recent deployment of the Alaska transportable array provides a new direction to illuminate the Hawaiian ULVZ using diffracted phases propagating from south to north. We identify five new events from the Kermadec Islands that are recorded in Alaska which show similar hyperbolic $S_{\text {diff }}$ postcursors to the previous events recorded in the central USA (Fig. S3). The symmetry of the postcursors suggests the Hawaiian ULVZ has an axisymmetric structure likely quasi-cylindrical in shape. In this case, the least delayed postcursors represent waves that have propagated through the center of the cylinder have not been refracted out of plane and thus show no additional travel-time delay due to extra path length. Based on the intersection of the minimally-delayed $\mathrm{S}_{\text {diff }}$ paths in two almost orthogonal directions, the ULVZ is located further to the southwest than previously thought, centered around $172.3^{\circ} \mathrm{W}$ and $15.4^{\circ} \mathrm{N}$. Long-period synthetics for this new location are computed using coupled-CSEM ${ }^{3}$ and compared to data from all events, shown in Fig. S2 and S3. Results show a good fit to the delay time and move-out of postcursors, although there is some variation between observed and modeled amplitudes, likely due to inaccuracies in the assumed sources and therefore $\mathrm{S}_{\mathrm{diff}}$ radiation patterns

\section{Sensitivity Kernel for $S_{\text {diff }}$ Wave at CMB}

The sensitivity kernel of a wave illustrates which part of the Earth affects the observed waveform. Some numerical software packages (i.e. SPECFEM_Global ${ }^{4,5}$ ) can now calculate the finitefrequency sensitivity kernels for specific phases. However, calculations for kernels at higher frequencies (i.e. up to $.33 \mathrm{~Hz}$ ) are still very challenging given current computational resources. Here we approach the high-frequency sensitivity kernels with a more heuristic analytical method. We note that the tangential component of the guided postcursor shear waves we observe near the $\mathrm{CMB}$ are analogous to surface Love waves, as both have free stress boundaries in the SH system. We apply the theory previously developed for Love waves in a vertically heterogeneous 
medium $^{6}$ to velocity profiles at the $\mathrm{CMB}$ to provide an estimate of the $\mathrm{S}_{\text {diff }}$ sensitivity kernel at different frequencies. We assume the wave coming from the mantle side is a quasi-plane wave of a specific frequency and wavenumber. We then extend the wave propagation from the lower $200 \mathrm{~km}$ to the CMB using the propagator matrix method. Making use of the boundary condition at the $\mathrm{CMB}$, we obtain the eigen wavenumber for each specific frequency and then transform them into a sensitivity kernel. Fig. S4 shows the eigensolutions of displacement and traction for $3 \mathrm{~s}-, 10 \mathrm{~s}-$, and 20 s-period waves. From the plot, we see that shorter periods have sensitivity closer to the CMB, with the 3s-period showing significant sensitivity to the lowermost $5 \mathrm{~km}$. These kernels have guided our proposed velocity models used to fit our multi-frequency observations.

\section{Beamforming Analysis}

Beamforming is an array method used to measure the incoming direction and slowness of a signal as it passes through an array ${ }^{7}$. We use beamforming not only to determine the direction of the incident wave, but also to enhance the energy of the original signal by stacking data using the measured incident direction to align specific phases. The beamforming stack (B) is given by:

$$
B(t, \theta)=a b s\left[H\left(\sum_{i=1}^{N} s_{i}\left(t-u(\theta) \bullet x_{i}\right)\right)\right]
$$

where $H$ represents the Hilbert transform on the stacked original data time series $s_{i}(t), u$ is the slowness vector as function of the incoming angle $\theta$, and $x_{i}$ is the distance vector to the reference station.

First, we apply this beamforming stacking on the original array data in order to determine the most likely incoming angle. Unlike other body waves, the $S_{\text {diff }}$ phase has a fairly constant slowness value for the grazing distances as long as the velocity variations are negligible at the diffraction exit points at the core-mantle boundary. We fix the absolute value of $\mathrm{S}_{\text {diff }}$ slowness $\underline{u}$ at $8.323 \mathrm{~s} / \mathrm{deg}$, as given by the IASP91 model $^{8}$, and search the incident direction in a range of $-\overline{50}$ to 50 degrees with respect to the incoming angle of the great circle path from the event epicenter provided by the TauP software ${ }^{9}$. We apply this procedure for each station by forming a sub-array consisting of the nearest 20 stations, or all stations within 4 degrees epicentral distance.

Fig. S5 shows examples of the resulting beamforming phase stacks. We find two separate energy peaks in the time range of main arrival and postcursor respectively. These two peaks locate at different beamforming directions, suggesting these two signals pass through the array with different incident angles. The record is kept only if we observe one dominant local maximum in the estimated arrival time window. The backazimuth directions and travel times for the maxima in our beamforming stacks are shown in Fig. 2BC and EF in the main text. To estimate the uncertainty of our fixed slowness, we repeat the procedure with slowness values varied by $\pm 5 \%$. The differences in measured backazimuth and travel time are given as error bars on our measurements.

\section{Waveform Stacking}

We produce final waveform stacks by multiplying the linear stack with a weighted phase stack using the observed incidence angle measurements of the main phase and postcursor, such that:

$$
g(t)=\frac{1}{N} \sum_{i=1}^{N} s_{i}\left(t-u \cdot x_{i}\right)\left\|\frac{1}{N} \sum_{k=1}^{N} \exp \left[i \Phi_{k}\left(t-u \cdot x_{i}\right)\right]\right\|^{v}
$$


where $s_{i}$ represents the time series of $i$-th station of an array, $x_{i}$ is the distance vector for $i$-th station with respect to the reference station, $u$ is the measured directional slowness vector for the reference station obtained from beamforming, and $\Phi_{k}$ denotes the instantaneous phase obtained from Hilbert transform of the original data time series $s_{i}(t)$. Weighting factor $V$ governs the sharpness of the noise reduction. To balance data distortion and signal coherency, we use $v=2$ in our processing, as recommended in ${ }^{10}$. We again stack over sub-arrays where $\mathrm{N}=20$ nearest stations, or all the stations within four degrees epicentral distance.

Because of the differences between our main arrival and postcursor phases, we have to split our stacked seismogram into two parts: the first window uses the measured main arrival incoming direction and the second window uses the measured postcursor incoming direction. The final stacked waveforms for all stations are shown in Fig. $2 \mathrm{~A}$ and $\mathrm{C}$ in the main text, with the two parts split by a dashed line. This procedure is applied for the two different frequency ranges explored, and significantly aids in bringing out a coherent postcursor signal in the 3-6 period range. For comparison to the stacked waveforms shown in Fig. 2, the raw data of event 20100320 is shown in Fig. S1.

\section{Wavelet Spectrum of the Stacked Seismograms}

The dispersive nature of the observed postcursors is difficult to observe in seismograms in the time domain. Here we use the wavelet spectrum, which is well-suited for non-stationary seismic data, to show the energy distribution of signals in both the frequency domain and the time domain. These spectra illustrate the stronger phase dispersion in the postcursor compared to the main $S_{\text {diff }}$ arrival. We perform a continuous wavelet transform using the complex Morlet wavelet on the stacked time series from 20s before to 120 s after the predicted $S_{\text {diff }}$ arrival time. Spectra of linear stacks and phase-weighted stacks based on main $\mathrm{S}_{\text {diff }}$ and postcusor incoming angles are compared in Figure S6. The phase-weighted stacks have a better signal-noise-ratio. The spectra show that most of the signal energy is distributed above 3s. We also observe a gap in energy near the period of $6 \mathrm{~s}$ in the data from event 20100320. It is based on these observations, that we define the two frequency ranges used in this study to demonstrate the dispersive nature of these phases: short-period at 3-6s, and long-period at 10-20s.

\section{Clustering of Beamforming Results}

The results from our beamforming backazimuth measurements show some scatter, thus we make use of a clustering algorithm (DBSCAN - density-based spatial clustering of applications with noise) to help threshold our short-period observations ${ }^{11}$. With no priori information on the data, the DBSCAN algorithm identifies the core sample and the outliers by measuring the neighborhood distance and density. If a point is closely connected to its topological neighbors, it will be treated as trustworthy. Conversely if a point is not reachable by many of the core points in the set within a given covering distance, it will be discarded as noise. This provides us a robust way of filtering measurements without any subjective manual data picking. The result of applying the DBSCAN algorithm to the observed deviations in backazimuth for the short-period postcursor is shown in Fig. S7. Our following misfit calculations only use the measurements deemed robust based on this method. 


\section{First Estimate of Basal ULVZ Properties}

Although calculating wave propagation through a 3D ULVZ model is a complicated process, we first estimate the basic properties of the base of the ULVZ using simple calculations of postcursor time delay. Along profile that samples the ULVZ center, multi-pathing effects are negligible. This provides us with a simple geometrical relationship that links the properties of the ULVZ with the arrival time delays:

$$
\delta t \sim \frac{2 r}{v} \frac{d v}{1-d v}
$$

where $r$ is the radius of the structure, $d v$ is the fractional velocity reduction, and $v$ is the background velocity at the CMB. This relationship is plotted in Figure S8 for the least delayed long-period and short-period postcursors. Results reveal that either extreme slow material as the base of the ULVZ or a ULVZ that is much wider at its base could explain the arrival times of delayed postcursors. If the bottom part of the ULVZ remains the same radius at $455 \mathrm{~km}$, the velocity reduction would be up to $30 \%$. If we otherwise assume the velocity reduction to remain constant at $20 \%$, then the material should be spread much more widely with a radius of $700 \mathrm{~km}$.

\section{Ray-based Modeling of the ULVZ}

Next, we use a ray-approximated method and the travel-time and backazimuth constraints from the refracted short-period postcursors to further estimate the properties of the lowermost part of the ULVZ structure. We only predict the horizontal wave propagation using the horizontal slowness and assume a full decoupling of the vertical propagation. The transmission of the wave is considered only where the ray enters and exits the ULVZ boundary. Figure S9 shows the refraction pattern caused by the cylindrical ULVZ and the predicted travel-times and backazimuths as a function of azimuth from the event.

With this computationally efficient tool, we are able to explore a large parameter space of radius and velocity reductions for the ULVZ, before computing more expensive full waveform synthetics. We implement a grid search varying the ULVZ velocity reduction from $15 \%$ to $50 \%$ in steps of $5 \%$, and its radius from $355 \mathrm{~km}$ to $855 \mathrm{~km}$ in $50 \mathrm{~km}$ steps. Figure S10 shows how well different combinations of ULVZ properties fit the short-period postcursor observations. Misfits are calculated based on the arrival times, the backazimuths, and a combination of the two. We choose to use the L1 norm in the misfit calculation, as it is more robust and resistant to outliers for a small number of samples.

In the travel-time misfit plot (Fig. S10A), we see the expected tradeoff between the velocity reduction and the ULVZ radius. The travel-time misfit suggests the cylindrical ULVZ to be either small, with an extreme velocity reduction (radius $405 \mathrm{~km},-50 \% \mathrm{dVs}$ ), or to be larger, with a more modest velocity reduction (radius $855 \mathrm{~km},-20 \% \mathrm{dVs}$ ). The backazimuth misfit also shows a tradeoff, but with the opposite orientation (Fig. S10B): requiring the ULVZ to be either small with slight velocity reduction (radius $455 \mathrm{~km},-15 \% \mathrm{Vs}$ ) or to be widespread and extremely reduced (radius $855 \mathrm{~km},-45 \% \mathrm{Vs}$ ). The combination of these two misfits normalized by each minimum value, creates a joint misfit which employs the two opposing trade-offs. This mistfit identifies the best-fitting intermediate model with a radius between $605 \mathrm{~km}$ to $755 \mathrm{~km}$ and a velocity reduction between $25 \%$ to $30 \%$ (Fig. S10C). The best-fit result peaks at radius $655 \mathrm{~km}$ 
and velocity reduction at $30 \%$. Misfits for a ULVZ of constant radius of $455 \mathrm{~km}$ are less good, but would predict a velocity reduction of $40-45 \%$.

\subsection{Synthetic Exploration of Basal Layer Thickness}

We build on initial ray-tracing based results to further explore the causative effect of the ULVZ lateral structure using AxiSEM 2.5D synthetics down to $3 \mathrm{~s}^{12}$. These synthetics allow us to capture the full finite-frequency sensitivity of the diffracted phases but are more computationally feasible in terms of exploring the model space than full 3D simulations. 2.5D models assume azimuthal symmetry and are only accurate in the event-station plane, such that out-of-plane effects cannot be captured. Thus we compare our synthetic results to the waves that have propagated through the center of the ULVZ without refracting, i.e. the postcursors waves with minimal delay times. These waves show a travel-time deviation of $12 \mathrm{~s}$ between the long- and short-period postcursors. We construct two end-member models for the mega-ULVZ structure: 1) a $455 \mathrm{~km}$ radius mega-ULVZ model with an extremely reduced basal-layer of $-40 \% \mathrm{dV}$, referred to as R455; 2) a similar sized ULVZ including a $655 \mathrm{~km}$ wide and $-30 \% \mathrm{dV}$ basal-layer reflecting the lateral spreading of the mega-ULVZ material, referred to as R655. We analyze how the height of the basal-layer in both models interacts with $S_{\text {diff }}$ waves by varying its thickness from 0 to $5 \mathrm{~km}$ (Fig. S11). We find that for model R455 the best fitting solution suggests a $2 \mathrm{~km}$ thick extreme basal-layer, while for model R655 a basal-layer thickness slightly above $2 \mathrm{~km}$ is suggested.

\section{Full 3D S Siff Synthetics}

Using our estimates of ULVZ properties from the above analyses, we create models for full 3D waveform modeling. A new hybrid method has recently been developed using a combination of wavefield injection and AxiSEM3D, which allows computation of the global wavefield with a small-scale 3D internal heterogeneity down to periods of $1 \mathrm{~s}^{13}$. This method stores the wavefield information at the injection boundary and then uses AxiSEM3D to compute the wavefield inside and outside the boundary. As demonstrated in the 2.5D synthetics, our $\mathrm{S}_{\text {diff }}$ observations are more sensitive to the vertical rather than lateral structure. Thus we explore several variations of the R455 model with internal vertical structure. With a careful treatment of the meshing on the kilometer scale, each of such synthetics takes 128 nodes, with 64 CPU per node, 24 hours to finish on the Cambridge HPC cluster. Testing the wider R655 ULVZ scenario would require a larger injection boundary, and thus even more computing resources.

We construct four different ULVZ models for comparison: a uniform ULVZ of $-20 \% \mathrm{dV}$ a gradient ULVZ varying from $-10 \% \mathrm{dV}_{\mathrm{S}}$ at the top to $-30 \% \mathrm{dV}_{\mathrm{S}}$ at the bottom, and a twolayered ULVZ with an upper $10 \mathrm{~km}$ at $-10 \% \mathrm{dV}$ and a bottom $10 \mathrm{~km}$ at $-30 \% \mathrm{dV}$, and a $20 \mathrm{~km}$ thick ULVZ model with an extreme $2 \mathrm{~km}$ basal layer of $-40 \% \mathrm{~d}$ based on our $2.5 \mathrm{D}$ modeling. In the main paper we show it is difficult to distinguish these models in broadband data, although dispersive postcursor energy can be observed (Fig. 3B). Fig. S12 shows the waveform filtered into the two period bands of interest. The 10s-20s waveforms are highly similar for all models, demonstrating that waves at these periods are unable to differentiate between models containing different kilometer-scale internal structure. Data filtered for the $3 \mathrm{~s}-6 \mathrm{~s}$ band show strong differences between the modeled waveforms. The uniform model has a postcusor around 40s after the main $S_{\text {diff }}$ phase. The postcusor for the two-layer model arrivals much later at roughly $60-70 \mathrm{~s}$. The postcursor of the gradient model and the $2 \mathrm{~km}$ extreme model overlap at arrival times 
around 50s-60s - similar to arrivals seen in our high-frequency observations. All postcursors in these four models show a dispersive nature, to varying extents, between $3 \mathrm{~s}$ to $10 \mathrm{~s}$ (Fig. S13). The uniform and two-layer models show the weakest and strongest dispersion respectively, while the gradient and $2 \mathrm{~km}$ extreme model show moderate dispersion, comparable to our observations. It should be noted that the main $\mathrm{S}_{\text {diff }}$ phase, unlike its associated postcursor, is not dispersive. 

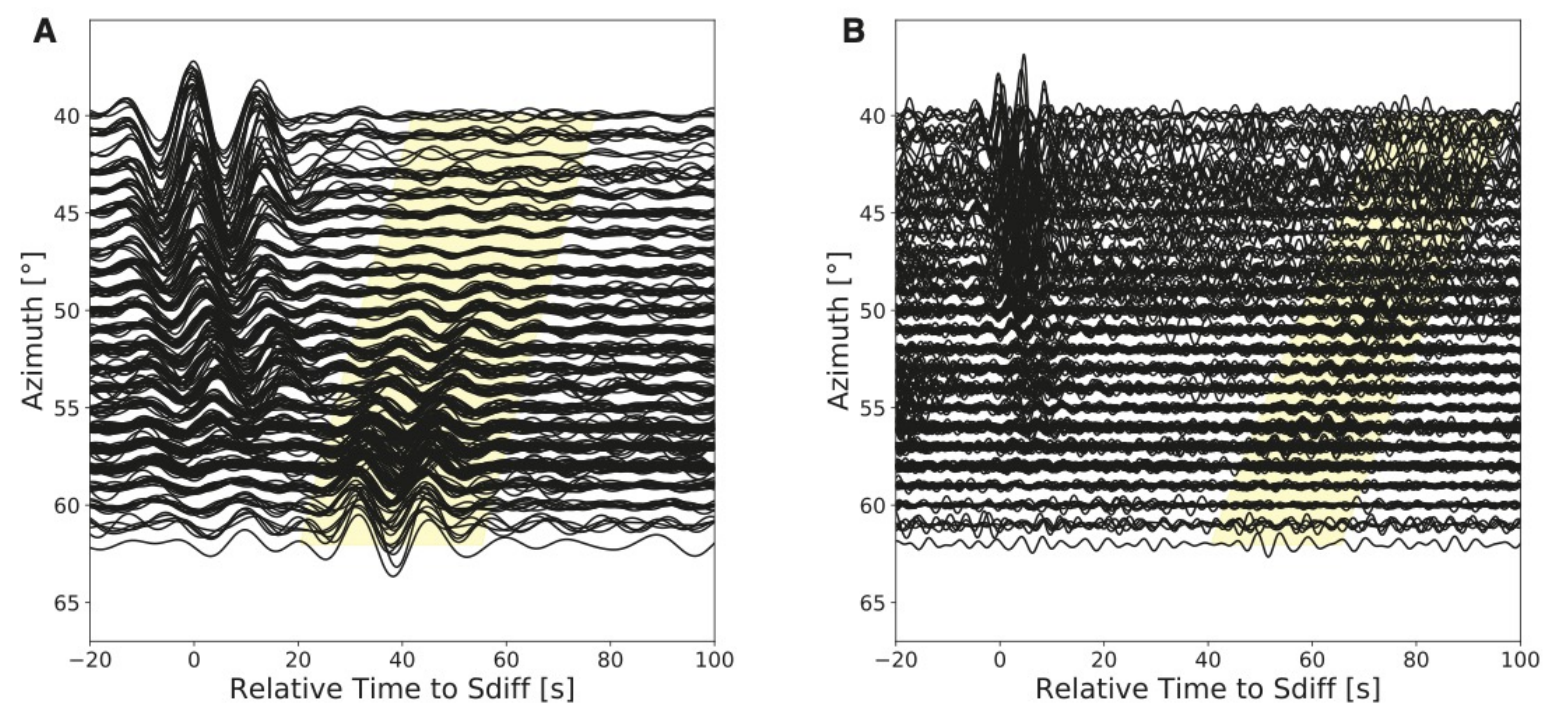

Fig. S1. Original data before stacking. Original data of Event 20100320 at $\mathrm{S}_{\text {diff }}$ distance $\left(100^{\circ}-\right.$ $110^{\circ}$ ) plotted as a function of azimuth, with time axis relative to predicted $\mathrm{S}_{\text {diff }}$ arrival time. (A) Filtered into long-period range $(10 \mathrm{~s}-20 \mathrm{~s})$ and (B) short-period range (3s - 6s). Yellow colored bands highlight the $\mathrm{S}_{\text {diff }}$ postcursor. 
A

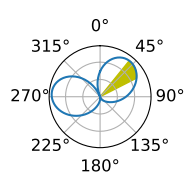

B

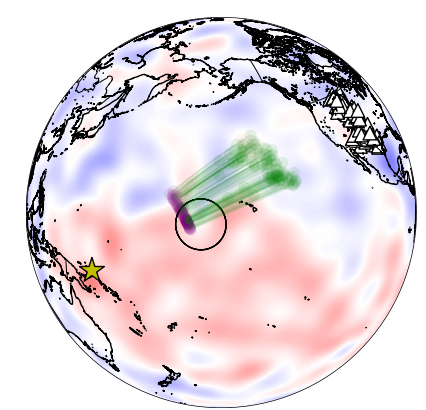

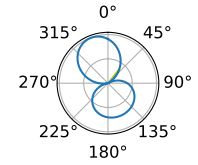

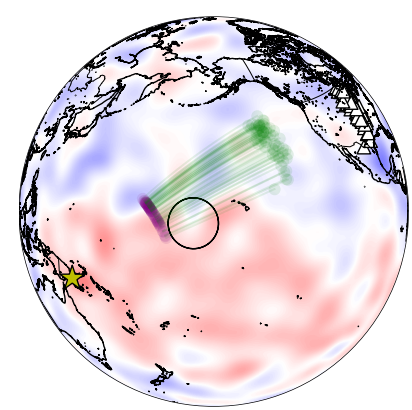

C
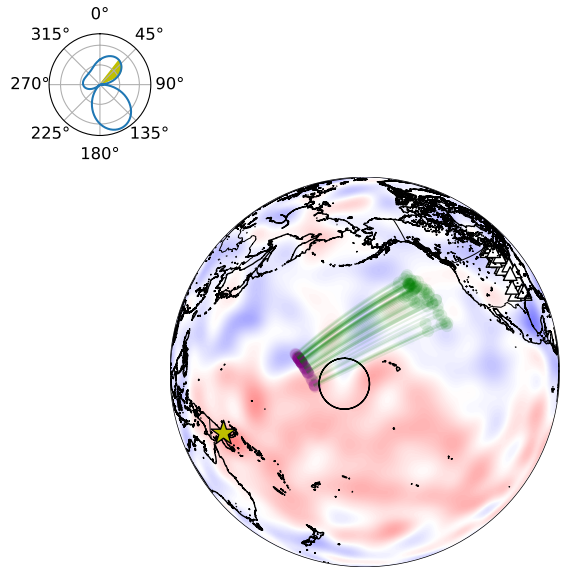
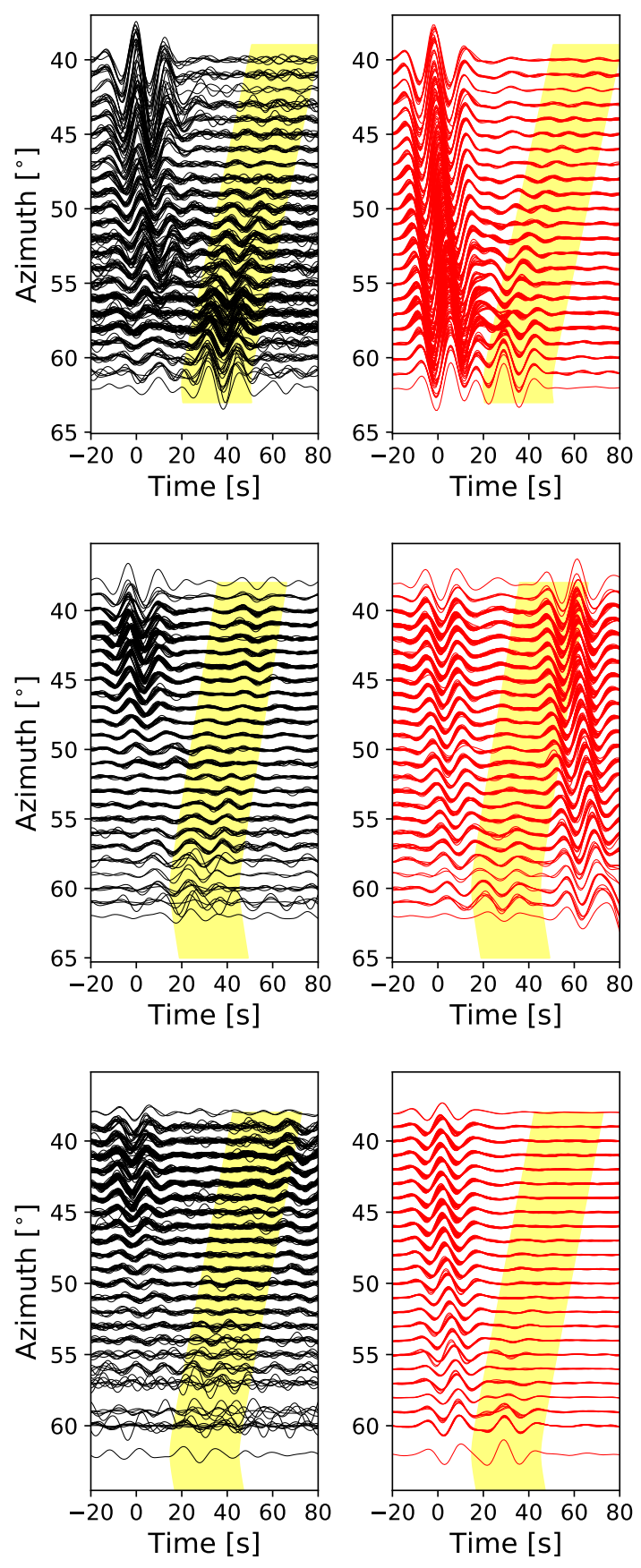

Fig. S2. Events used in this study recorded by the central USarray. For events: (A)20100320 (B)20111214 (C)20120417. On the left we show event radiation patterns (blue) with azimuth range for which data is shown highlighted (yellow). Next is the ray-path geometry shown between the entry (purple) and exit (green) points to the lowermost $100 \mathrm{~km}$ of the mantle, the event location (yellow star) and station locations (white triangles). Background shows tomography model SEMUCB_WM1 at $2800 \mathrm{~km}^{14}$. The right panels show the observed waveform data (black, left) and CSEM synthetics (red, right) filtered from 10s to 20s. Yellow colored bands highlight the $\mathrm{S}_{\text {diff }}$ postcursor. 
A

$$
\text { A275 }
$$

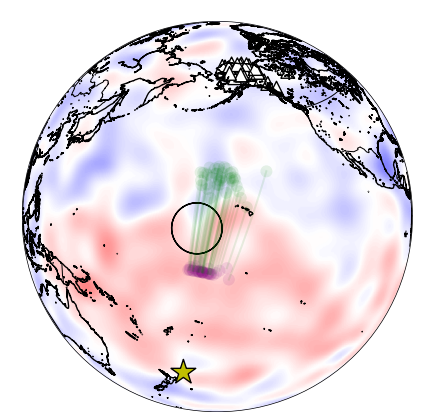

B

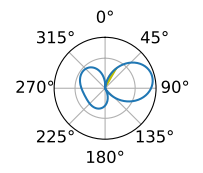

C

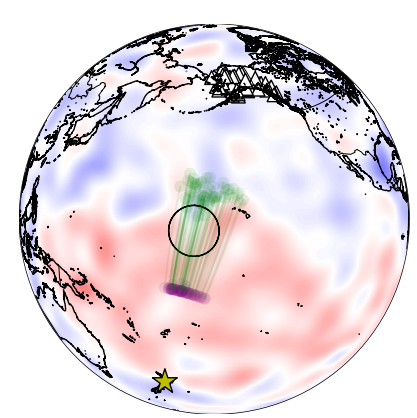

$$
\text { (220 }
$$

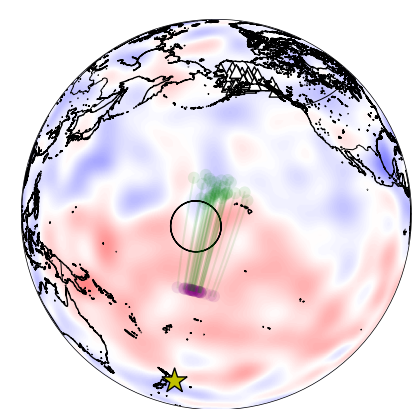

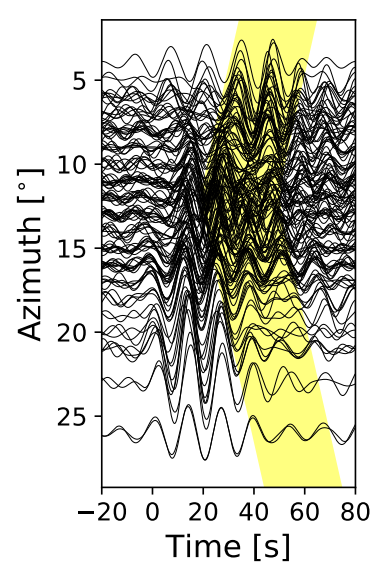
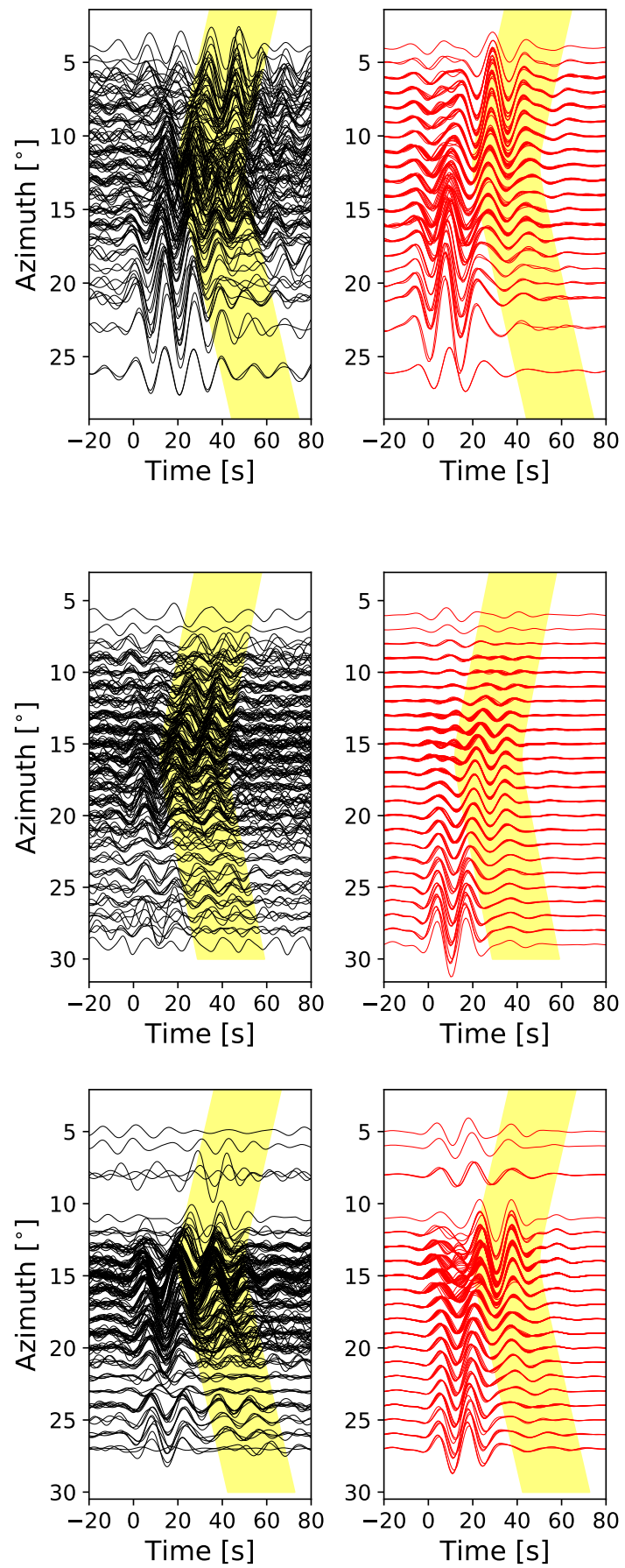

Fig. S3. As for Fig. S2 but for events recorded by the Alaska transportable array. For events: (A)20180518 (B)20181030 (C)20161122 (D)20180910 (E)20161113 
Submitted Manuscript: Confidential

D
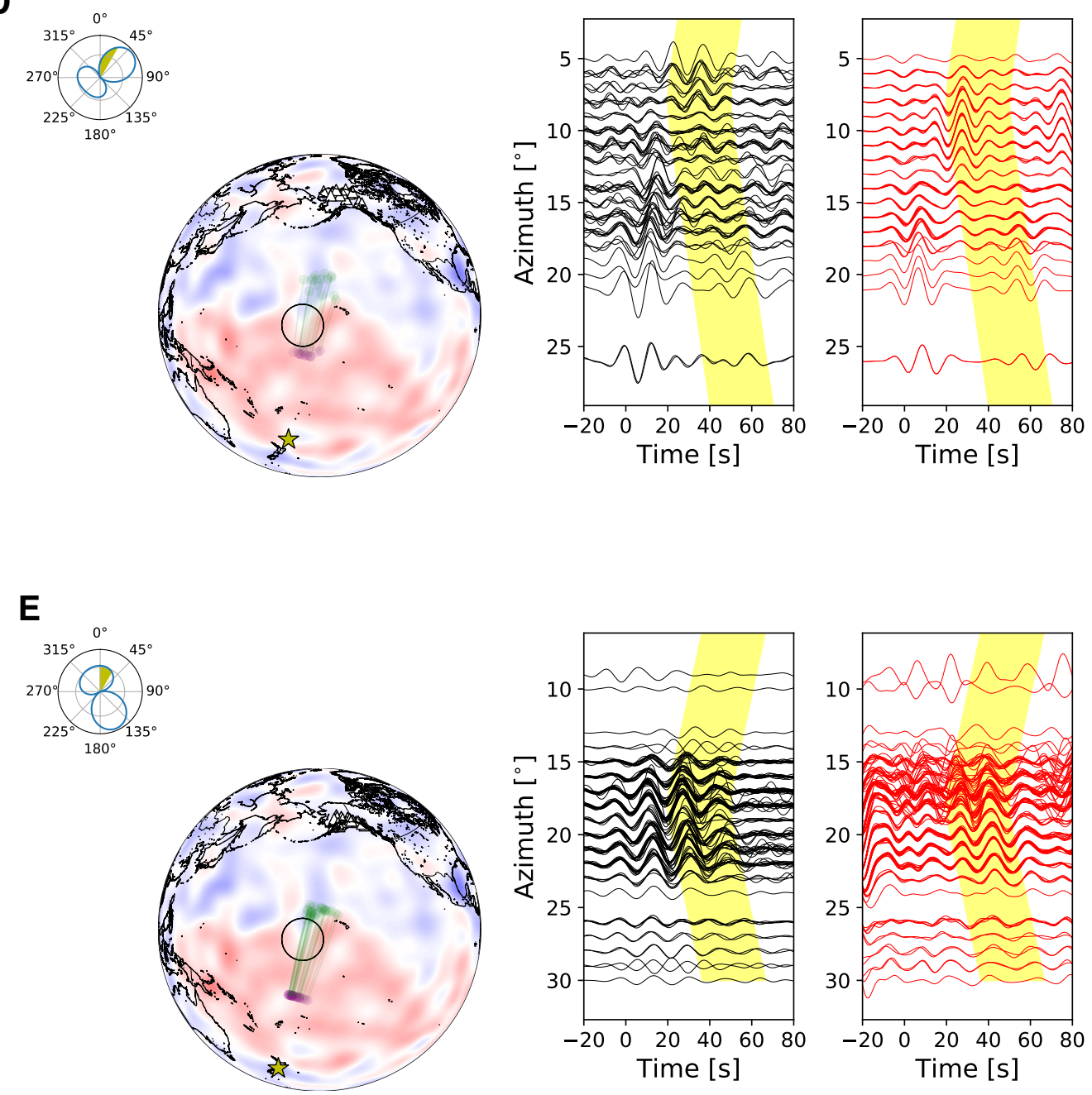

Fig. S3. (cont.) 
Submitted Manuscript: Confidential
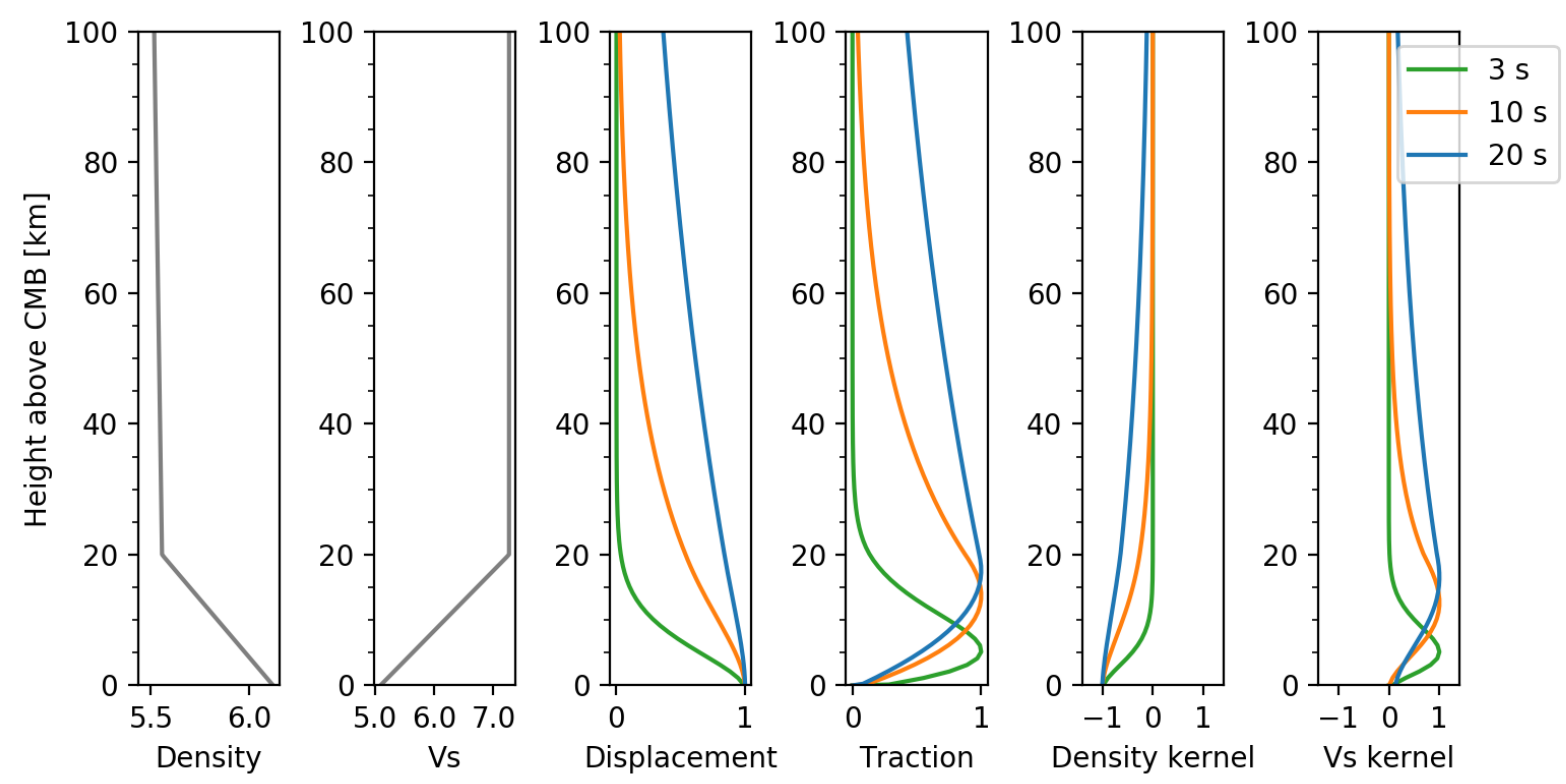

Fig. S4. Estimated sensitivity kernels for a $\mathbf{S}_{\text {diff }}$ wave above the $C M B$. From left to right: density profile, shear wave velocity profile, normalized eigen displacement, traction, density kernel and shear wave velocity kernels for a $3 \mathrm{~s}$ (green), 10s (orange) and 20s (blue) period $\mathrm{S}_{\text {diff }}$ wave in the bottom $100 \mathrm{~km}$ of the mantle. 

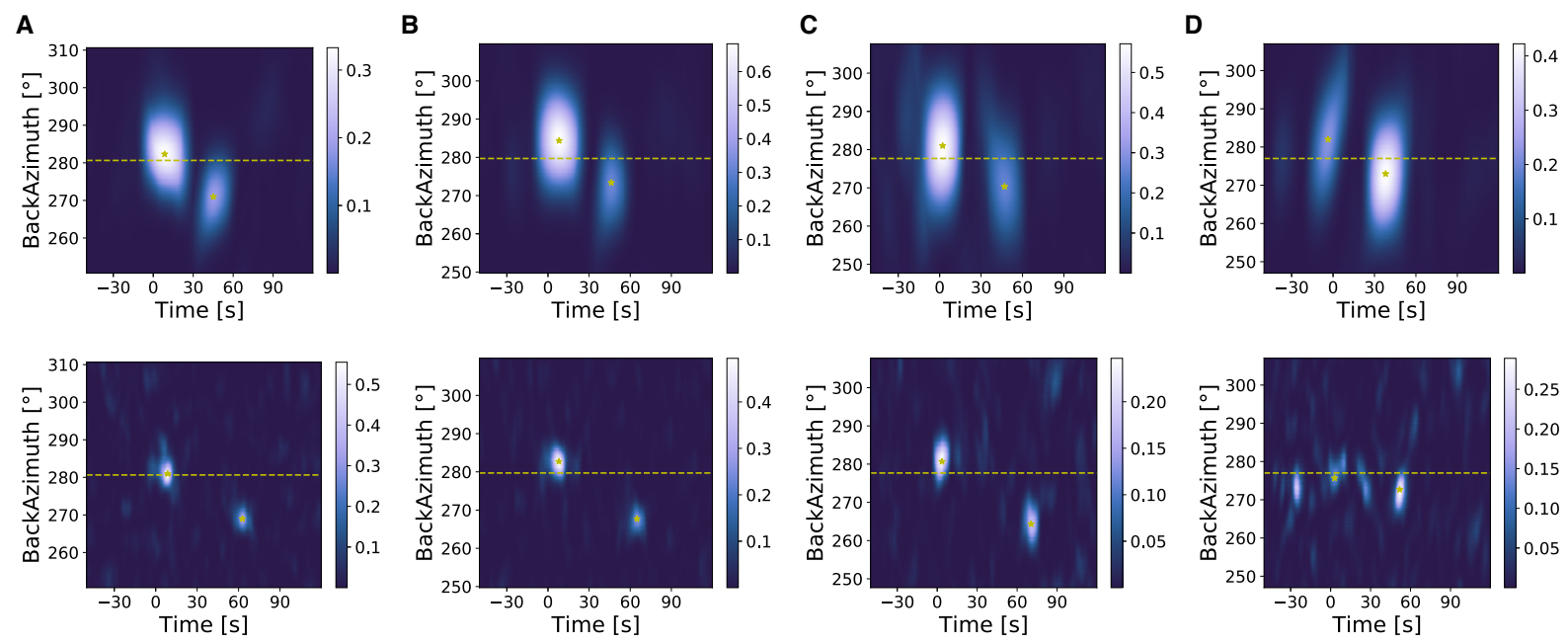

Fig. S5. Beamforming analysis of $S_{\text {diff }}$ main arrivals and postcursors in event $A$ from four example sub-arrays. (A) Station TUL1 in the transportable array at distance $109.66^{\circ}$ and azimuth $52.93^{\circ}$ (B) Station U34A in the transportable array at distance $108.19^{\circ}$ and azimuth $52.64^{\circ}$ (C) Station Q28A in transportable array at distance $104.44^{\circ}$ and azimuth $50.46^{\circ}$ (D) Station $232 \mathrm{~A}$ in transportable array at distance $107.10^{\circ}$ and azimuth $57.62^{\circ}$. Colors represent the beamforming energy. The yellow dashed line shows the predicted incoming direction. The picked incoming backazimuths and arrival times for the main phase and postcursor are marked with the yellow stars. Top panels show the result for long-period data, bottom panels show the result for short-period data. 


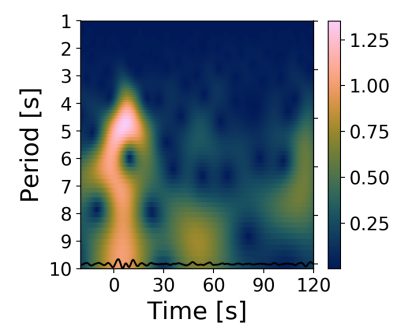

B

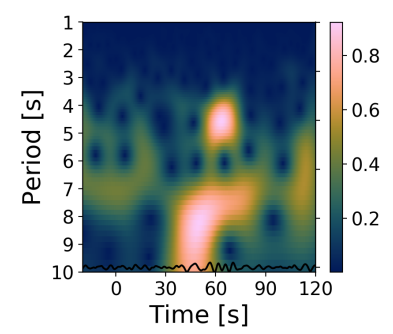

C

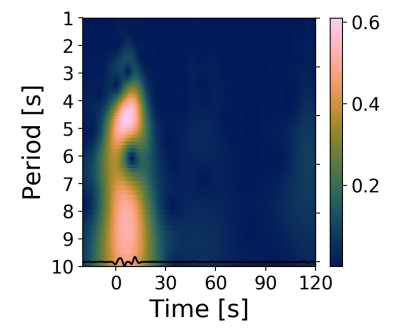

D

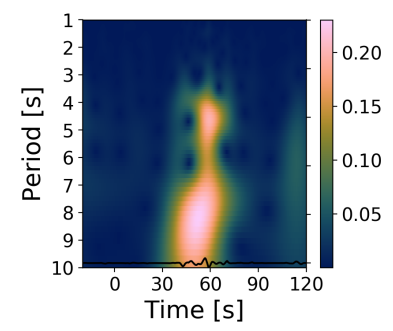

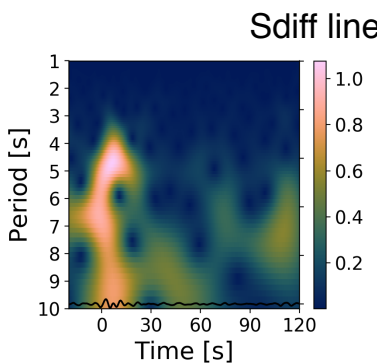
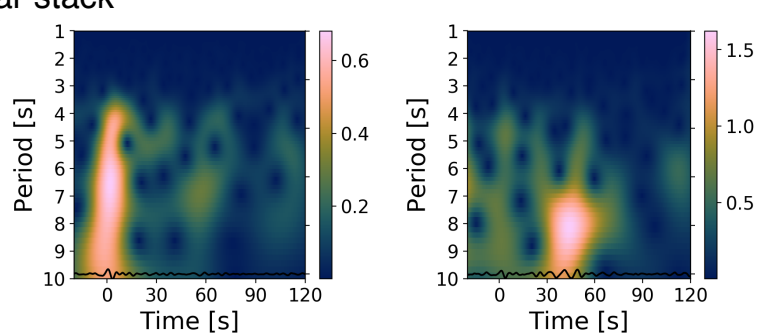

postcusor linear stack
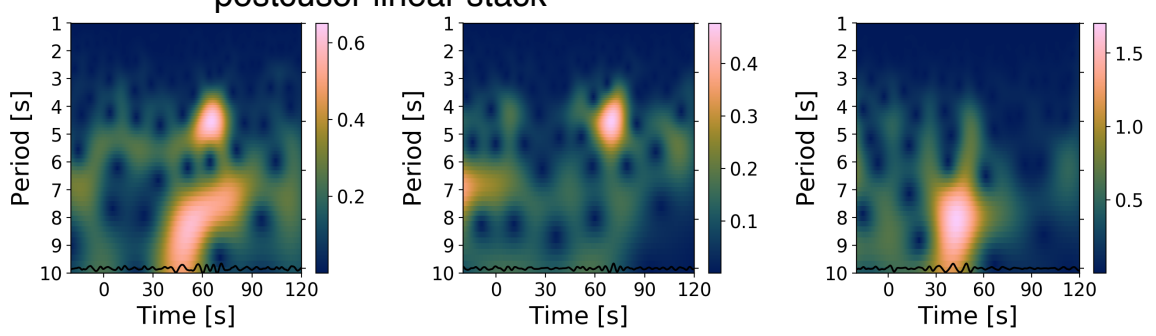

Sdiff phase weighted stack
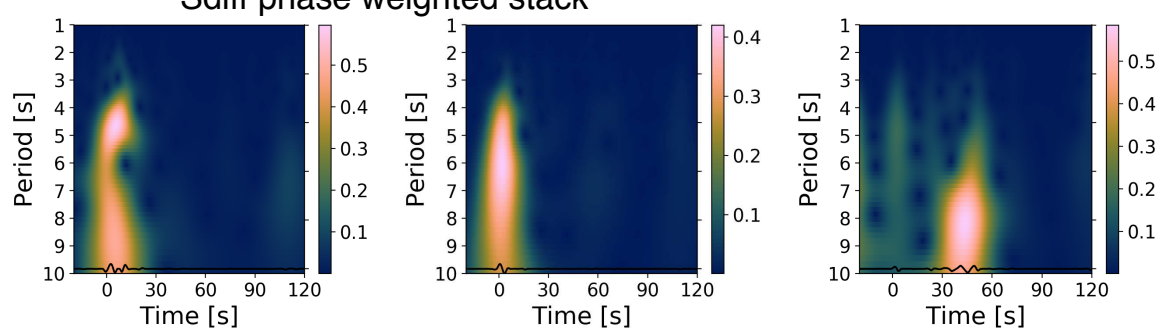

postcusor phase weighted stack
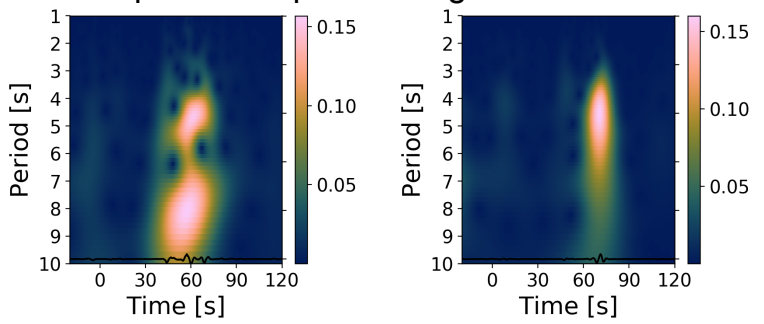

Fig. S6. Stacked wavelet spectrum for the four sample sub-array stacks in Fig.S5 for the 20100320 event. (A) Linear stacked wavelet spectrum using the main arrival incoming direction (B) Linear stacked wavelet spectrum using the postcursor incoming direction (C) Phaseweighted stacked wavelet spectrum using the main arrival incoming direction (D) Phaseweighted stacked wavelet spectrum using the postcursor incoming direction 


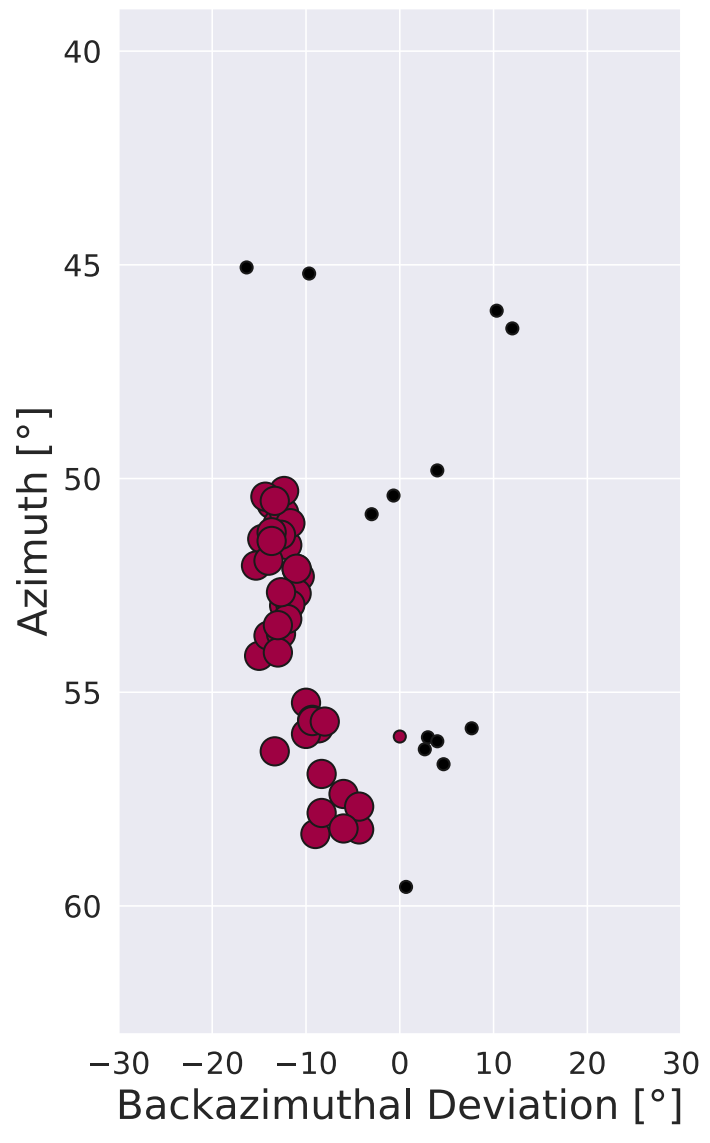

Fig. S7. Results of the clustering algorithm (DBSCAN) on the observed postcursor backazimuthal deviations. The large pink circles are the core points from our measurements. The small pink dots are non-core points which are reachable from the core points. The black dots are identified as outliers. 


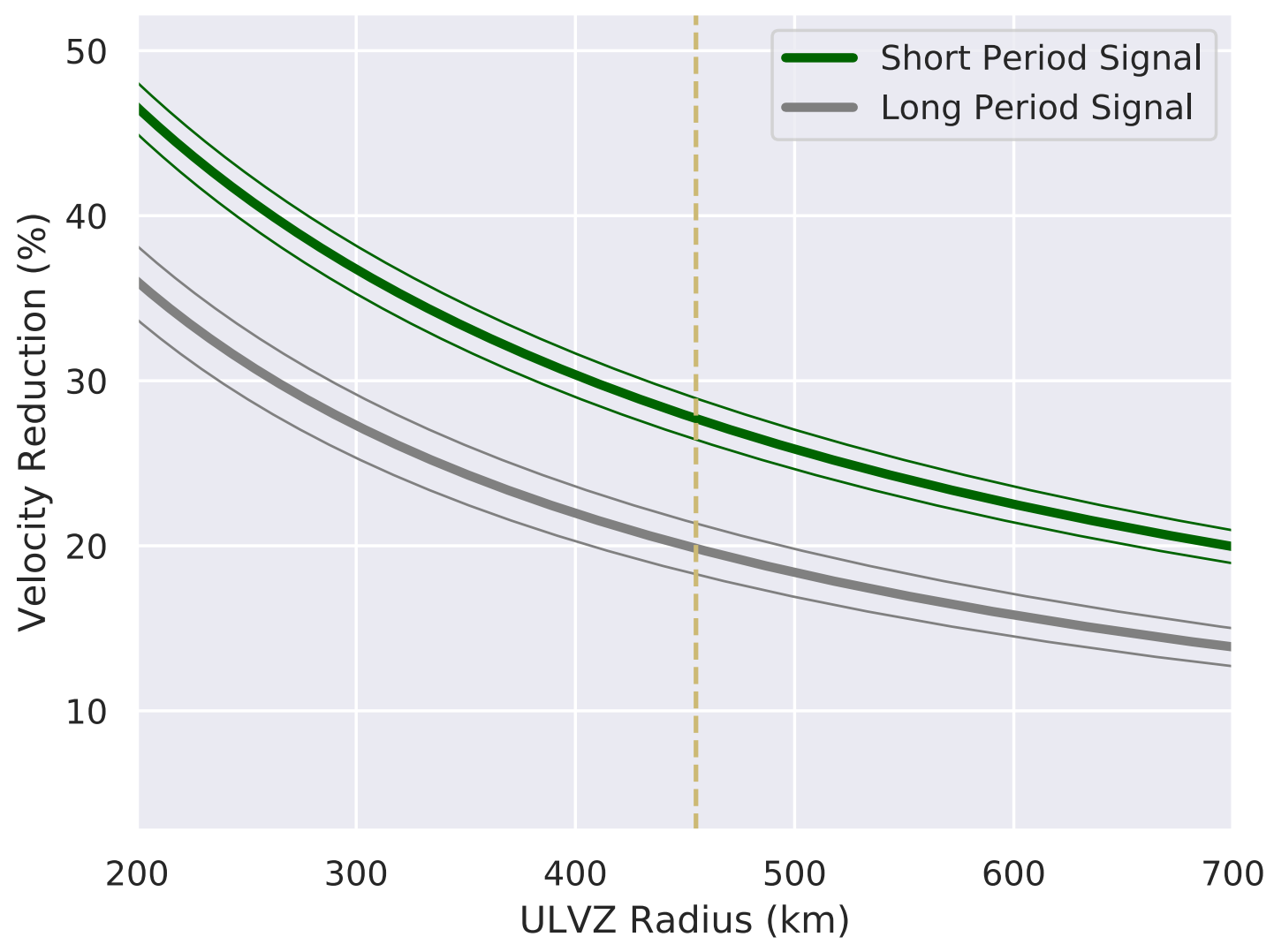

Fig. S8. Trade-offs between velocity reduction and ULVZ radius. This calculation is based on a simple cylindrical ULVZ structure and ray-theoretical assumptions. The green line indicates the tradeoff based on the observed short-period postcursor arrival time, while the gray line shows the long-period tradeoff. The thin line marks an uncertainty of $\pm 3 \mathrm{~s}$. The vertical yellow dashed line shows the radius of the favored ULVZ model in the study of ${ }^{2}$. 

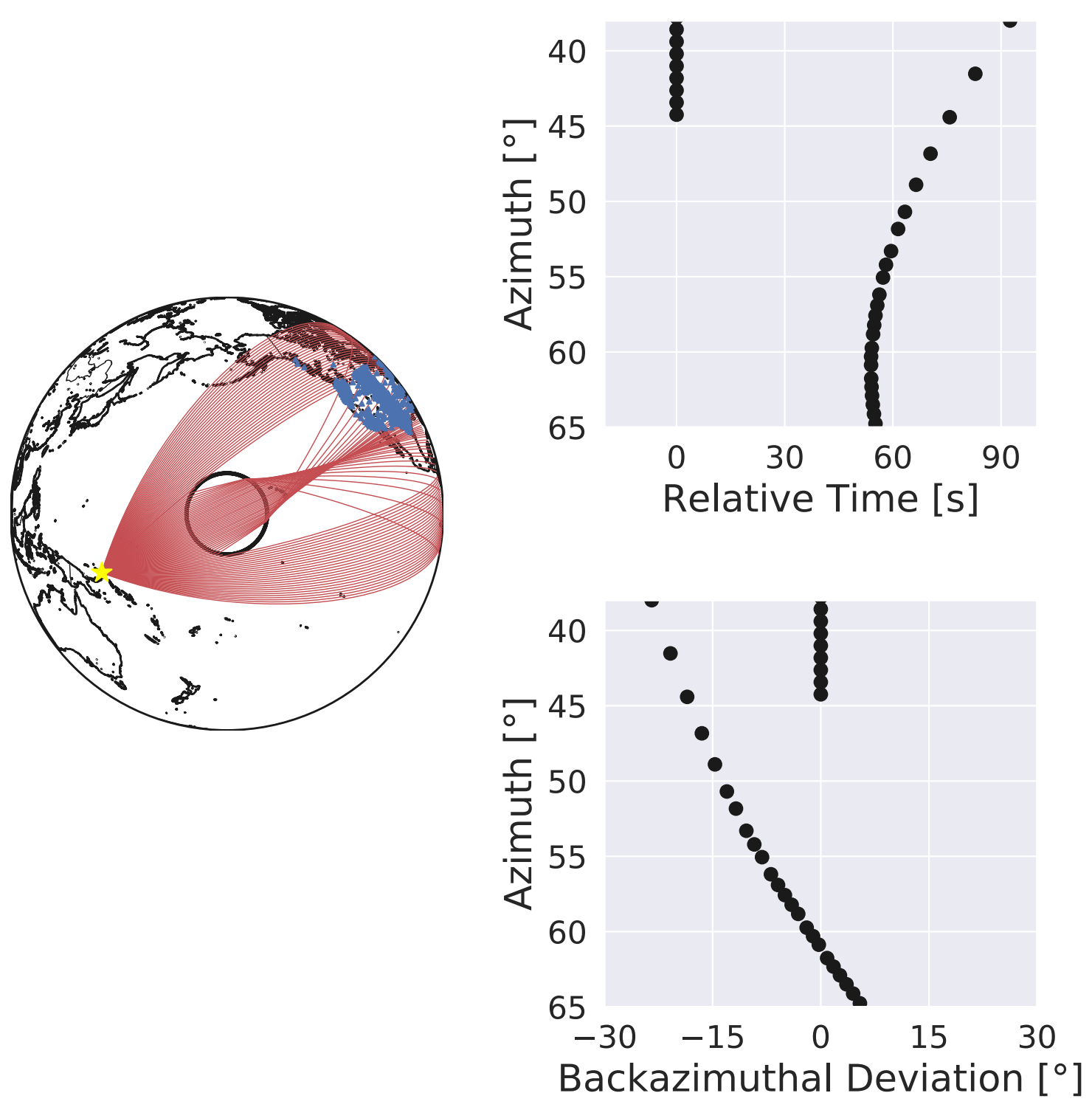

Fig. S9. Ray-based modelling of travel-time and backazimuth. The left shows the ray geometry focused by a cylindrical ULVZ. The upper right shows the travel-times of the rays as a function of the azimuth at the receiving station. The lower right shows the backazimuth deviation of the rays bent by the ULVZ structure. 
Submitted Manuscript: Confidential

A

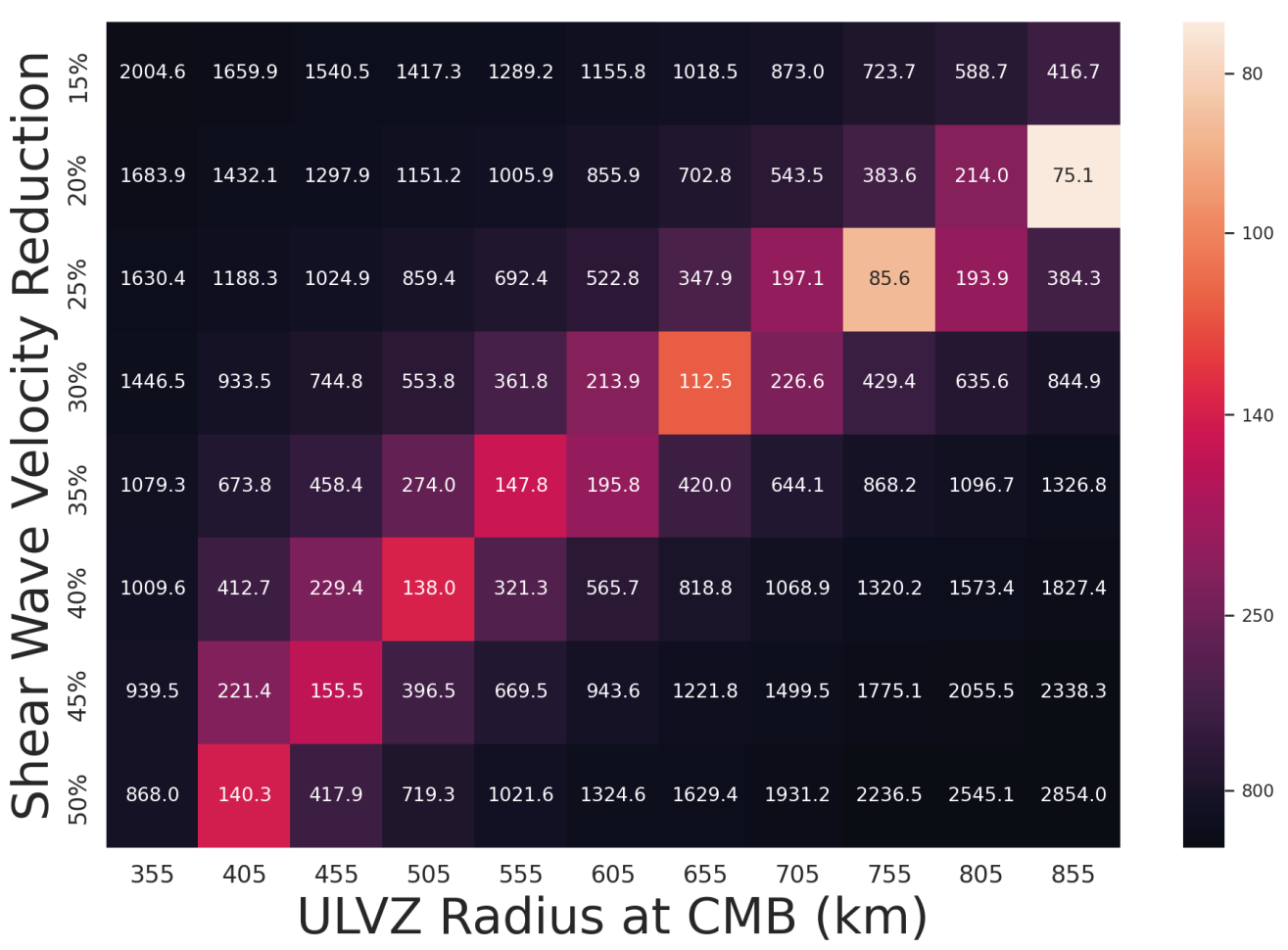

B

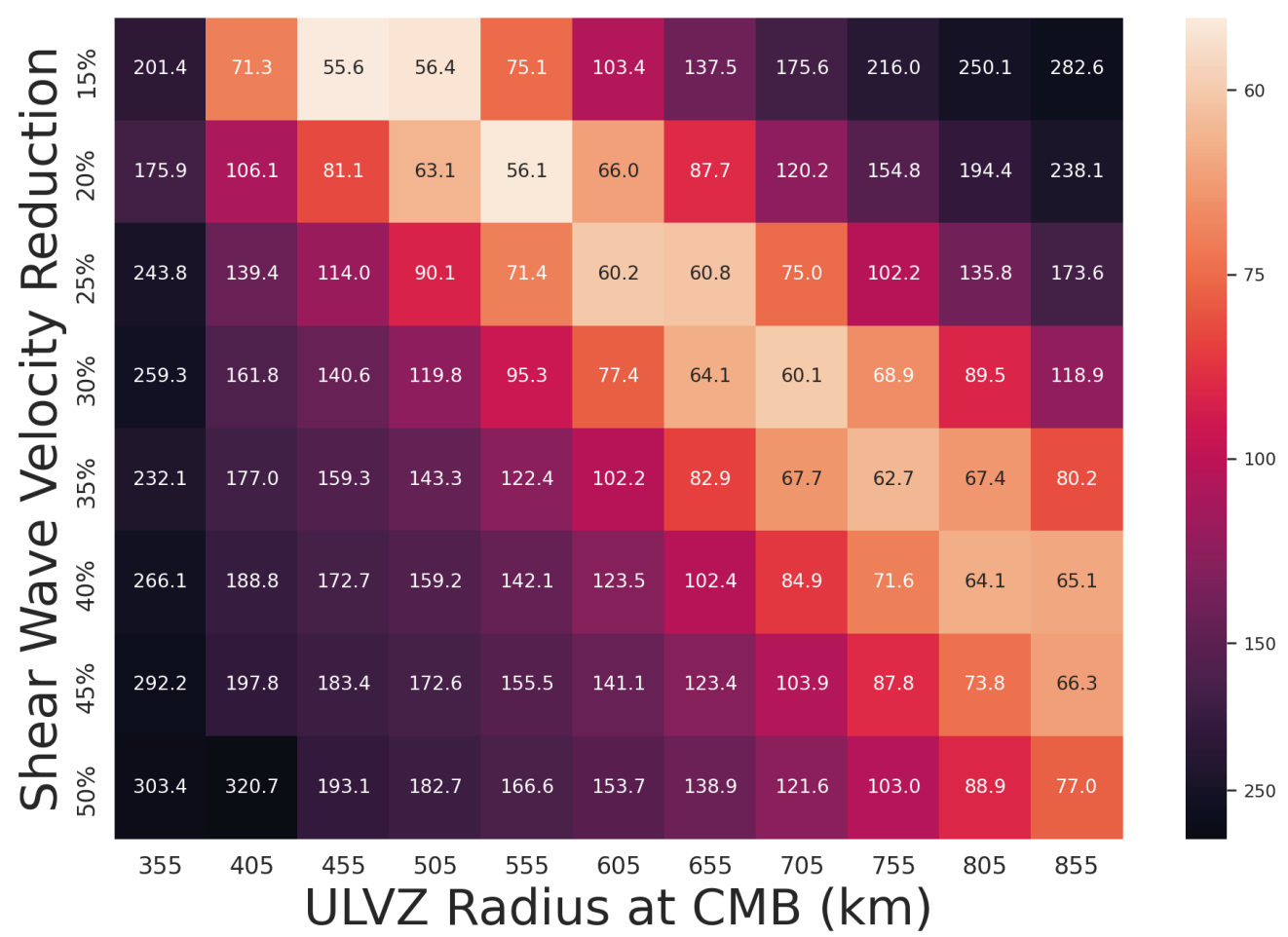

Fig. S10. Misfit colormap of the short-period data for ULVZ models of varying radius and velocity reduction calculated using raytracing. For misfits based on: (A) postcursor arrival time (B) postcursor backazimuth (C) joint misfit for arrival time and backazimuth. 
Submitted Manuscript: Confidential

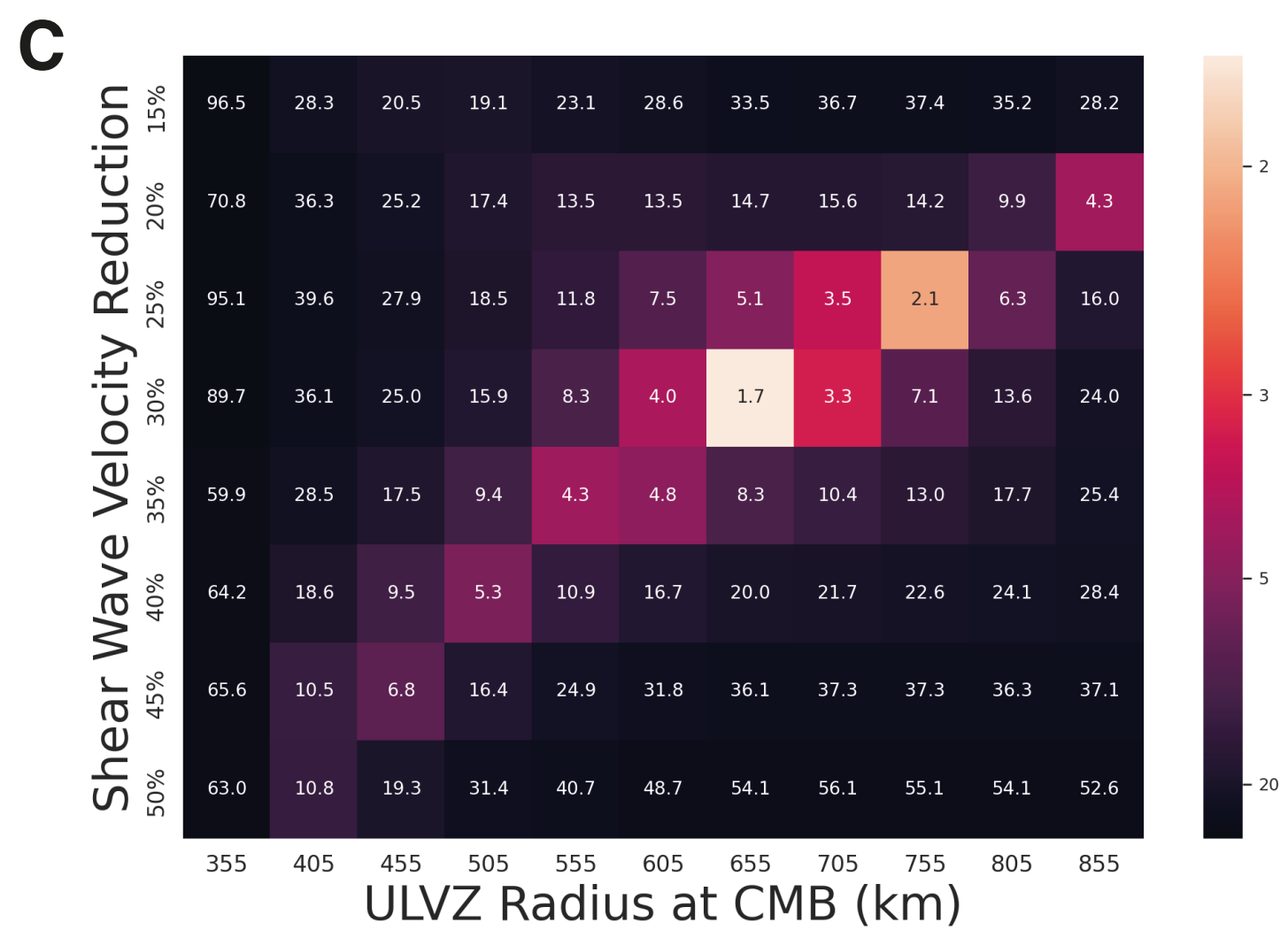

Fig. S10. (cont.) 
A
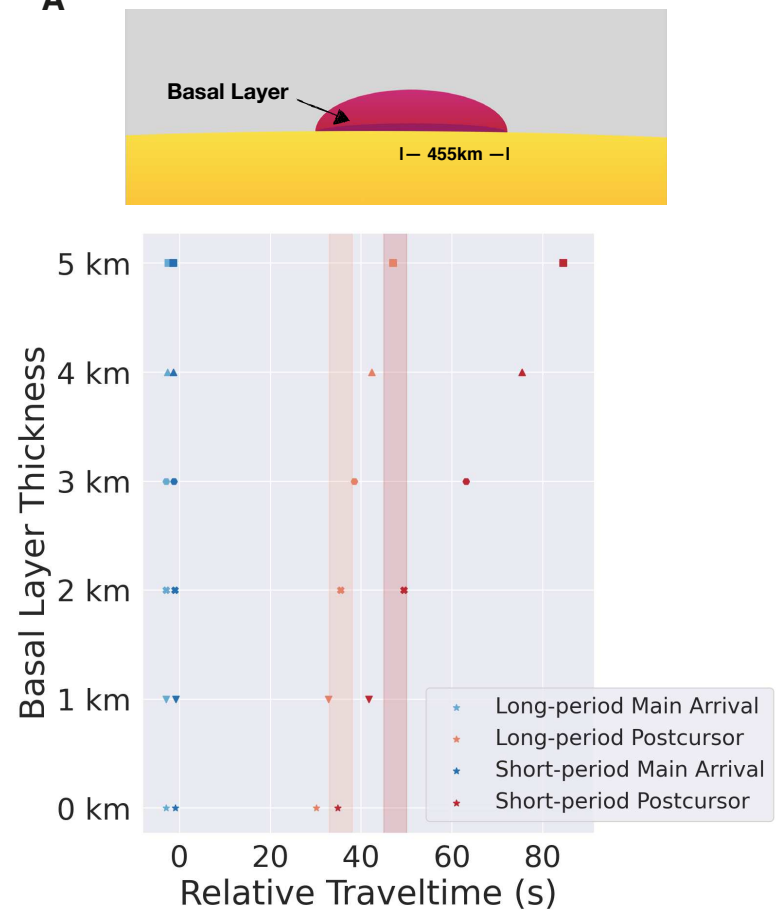

B
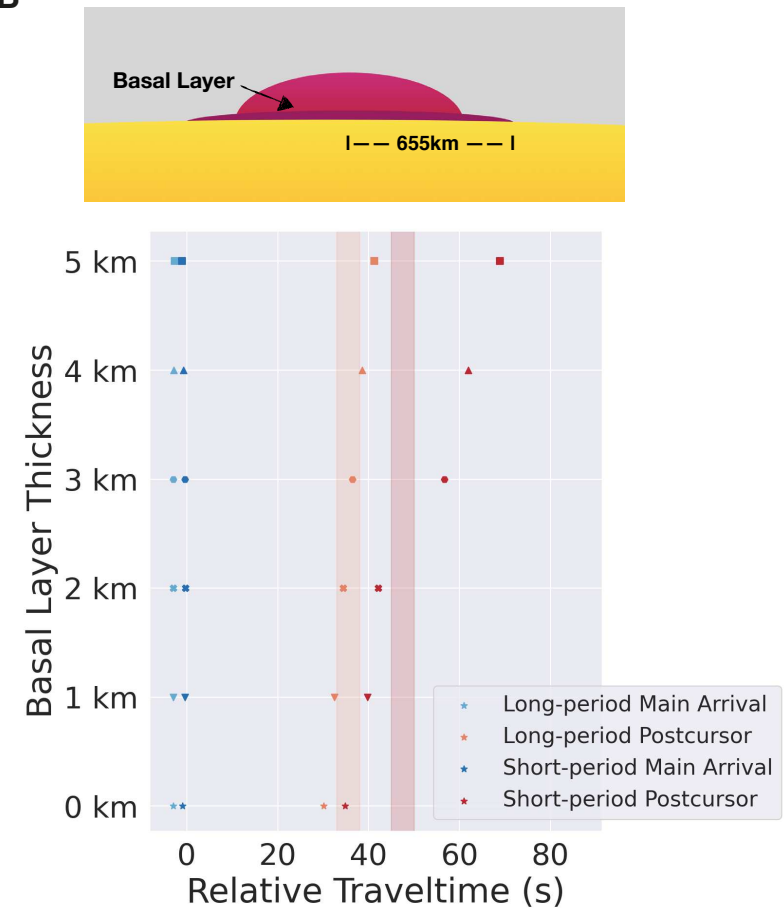

Fig. S11. Observed travel-times for postcursors 2.5D AxiSEM synthetics for two-layered ULVZ models with different basal layer thickness. The faded color bands show the observed arrival time of long-period (orange) and short-period (red) postcursors (A) Two-layered models with constant $455 \mathrm{~km}$ radius. The bottom $-40 \% \mathrm{dVs}$-layer varies from 0 to $5 \mathrm{~km}$ thick below a total thickness $20 \mathrm{~km}-20 \% \mathrm{dVs}$ layer. (B) Same as (A) but with a wider bottom layer of $655 \mathrm{~km}$ radius. 

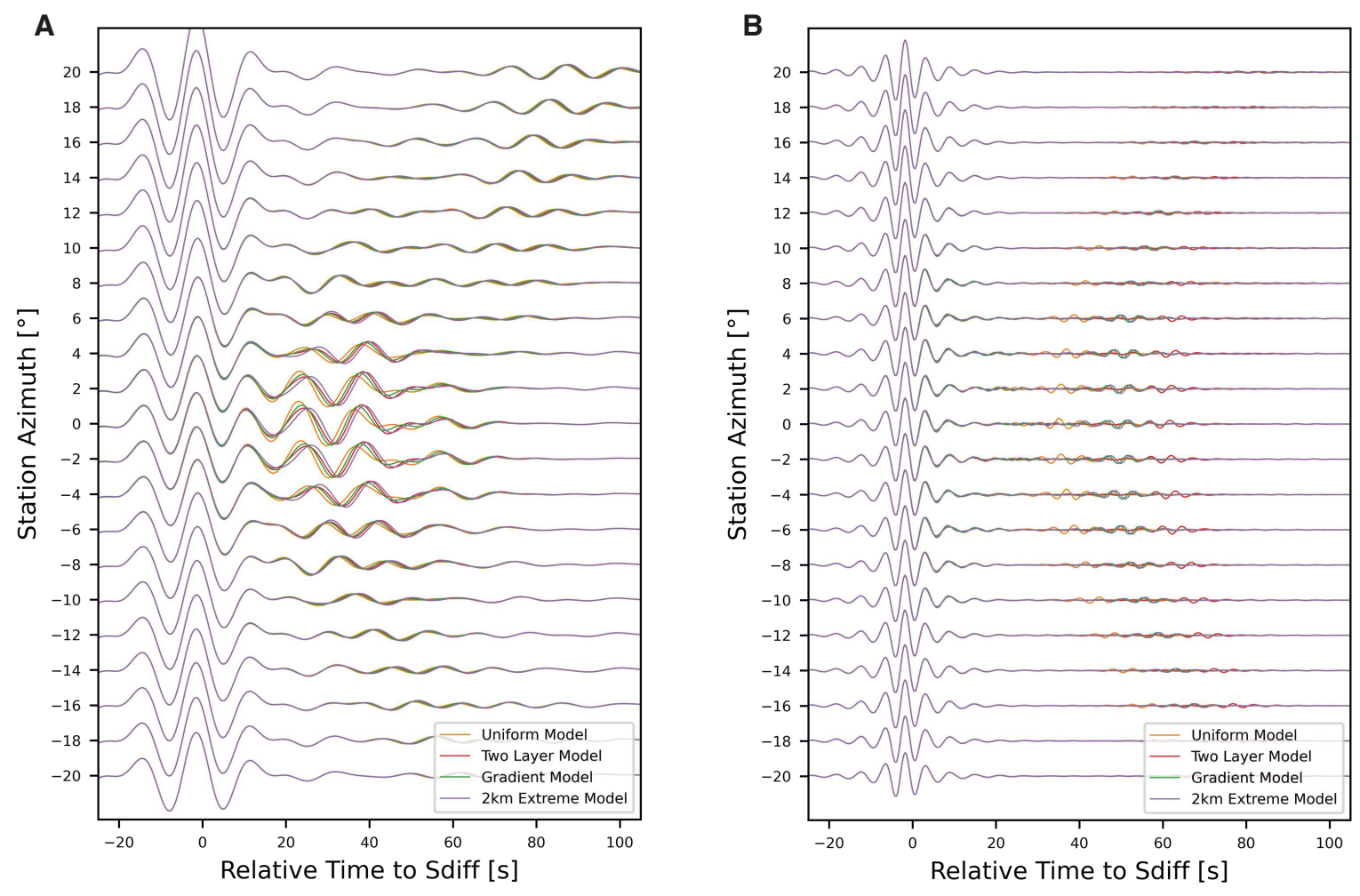

Fig. S12. 3D Synthetic waveforms of different ULVZ models plotted as function of station azimuth. Synthetics are for a uniform model of $20 \mathrm{~km}$ with $-20 \% \mathrm{dVs}$ (orange), a two-layer model of $10 \mathrm{~km}-10 \% \mathrm{dVs}$ layer on top plus a $10 \mathrm{~km}-30 \% \mathrm{dVs}$ layer at bottom (red), a $20 \mathrm{~km}$ gradient model changing gradually with ULVZ height from $-10 \%$ to $-30 \% \mathrm{dVs}$ (green), and a extreme $2 \mathrm{~km}-40 \% \mathrm{dVs}$ basal layer (purple) within a ULVZ of $20 \mathrm{~km}$ thickness with $-20 \% \mathrm{dVs}$. Synthetic waveforms filtered into the (A) long-period range (10s - 20s) and (B) short-period range (3s-6s). See also Fig. 3 for cartoons of models. 

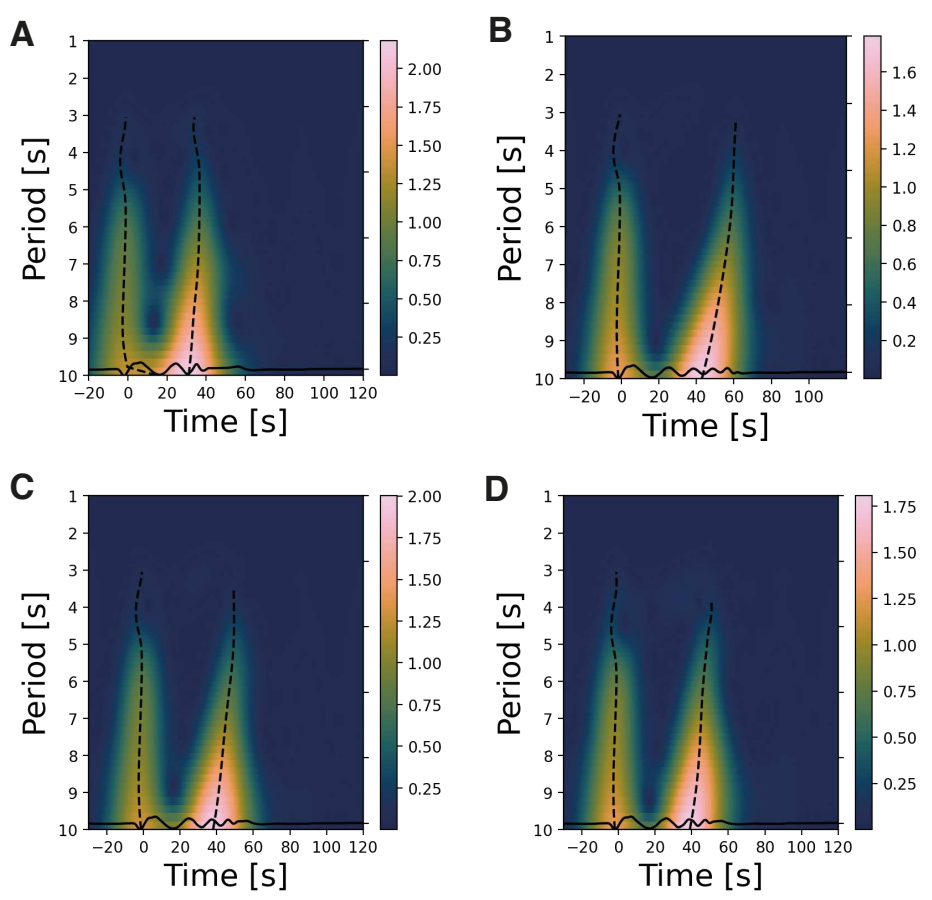

Fig. S13. Wavelet spectrums of single synthetic waveforms for four 3D ULVZ models sampling the center of the ULVZ. (A) the uniform model (B) the two-layer model (C) the gradient model (D) the extreme $2 \mathrm{~km}$ model. These spectra can be compared to the real data stacks in Fig. S6. 
Table S1.

Events used in this study. Source information is obtained from the global CMT catalog. (http://www.globalcmt.org/). Event 20100320 shows the strong dispersion in the postcursor presented in the main paper.

\begin{tabular}{|c|c|c|c|c|c|c|}
\hline Event & Region & $\begin{array}{l}\text { Date and } \\
\text { time (UTC) }\end{array}$ & $\begin{array}{l}\text { Latitude } \\
\left({ }^{\circ}\right)\end{array}$ & $\begin{array}{l}\text { Longitude } \\
\left({ }^{\circ}\right)\end{array}$ & $\begin{array}{l}\text { Depth } \\
(\mathrm{km})\end{array}$ & $\begin{array}{l}\text { Magnitude } \\
\left(\mathrm{M}_{\mathrm{W}}\right)\end{array}$ \\
\hline 20100320 & $\begin{array}{l}\text { New } \\
\text { Ireland } \\
\text { Region, } \\
\text { P.N.G. }\end{array}$ & $\begin{array}{l}2010-03-20 \\
14: 00: 50\end{array}$ & -3.32 & 152.33 & 413 & 6.6 \\
\hline 20111214 & $\begin{array}{l}\text { Eastern } \\
\text { New } \\
\text { Guinea } \\
\text { Reg., } \\
\text { P.N.G. }\end{array}$ & $\begin{array}{l}2011-12-14 \\
05: 04: 59\end{array}$ & -7.49 & 146.83 & 133 & 7.1 \\
\hline 20120417 & $\begin{array}{l}\text { Eastern } \\
\text { New } \\
\text { Guinea } \\
\text { Reg., } \\
\text { P.N.G. }\end{array}$ & $\begin{array}{l}2012-04-17 \\
07: 13: 49\end{array}$ & -5.66 & 147.16 & 209 & 6.8 \\
\hline 20180518 & $\begin{array}{l}\text { South Of } \\
\text { Kermadec } \\
\text { Islands }\end{array}$ & $\begin{array}{l}2018-05-18 \\
01: 45: 31\end{array}$ & -34.67 & -178.21 & 14.3 & 6.1 \\
\hline 20181030 & $\begin{array}{l}\text { North } \\
\text { Island, } \\
\text { New } \\
\text { Zealand }\end{array}$ & $\begin{array}{l}2018-10-30 \\
02: 13: 39\end{array}$ & -39.07 & 174.94 & 226 & 6.1 \\
\hline 20161122 & $\begin{array}{l}\text { North } \\
\text { Island, } \\
\text { New } \\
\text { Zealand }\end{array}$ & $\begin{array}{l}2016-11-22 \\
00: 19: 43\end{array}$ & -40.79 & 177.58 & 12.0 & 5.9 \\
\hline 20180910 & $\begin{array}{l}\text { Kermadec } \\
\text { Islands } \\
\text { Region }\end{array}$ & $\begin{array}{l}2018-09-10 \\
04: 19: 02\end{array}$ & -31.91 & -179.13 & 119 & 6.9 \\
\hline 20161113 & $\begin{array}{l}\text { South } \\
\text { Island, } \\
\text { New } \\
\text { Zealand }\end{array}$ & $\begin{array}{l}2016-11-13 \\
11: 02: 56\end{array}$ & -42.03 & 173.85 & 18.8 & 7.8 \\
\hline
\end{tabular}




\section{References}

1. Krischer, L. et al. ObsPy: A bridge for seismology into the scientific Python ecosystem. Comput. Sci. Discov. 8, 14003 (2015).

2. Cottaar, S. \& Romanowicz, B. An unsually large ULVZ at the base of the mantle near Hawaii. Earth Planet. Sci. Lett. 355-356, 213-222 (2012).

3. Capdeville, Y., Chaljub, E., Vilotte, J. P. \& Montagner, J. P. Coupling the spectral element method with a modal solution for elastic wave propagation in global earth models. Geophys. J. Int. 152, 34-67 (2003).

4. Komatitsch, D. \& Tromp, J. Spectral-element simulations of global seismic wave propagation - I. Validation. Geophys. J. Int. 149, 390-412 (2002).

5. Tromp, J., Tape, C. \& Liu, Q. Seismic tomography, adjoint methods, time reversal and banana-doughnut kernels. Geophys. J. Int. 160, 195-216 (2005).

6. Aki, K. \& Richards, P. G. Quantitative seismology. (2002).

7. Rost, S. Array seismology: Methods and applications. Rev. Geophys. 40, 1008 (2002).

8. Kennett, B. L. N. \& Engdahl, E. R. Traveltimes for global earthquake location and phase identification. Geophys. J. Int. 105, 429-465 (1991).

9. Crotwell, H. P., Owens, T. J. \& Ritsema, J. The TauP Toolkit: Flexible Seismic Traveltime and Ray-path Utilities. Seismol. Res. Lett. 70, 154-160 (1999).

10. Schimmel, M. \& Paulssen, H. Noise reduction and detection of weak, coherent signals through phase-weighted stacks. Geophys. J. Int. 130, 497-505 (1997).

11. Ester, M., Kriegel, H.-P., Sander, J. \& Xu, X. A Density-Based Algorithm for Discovering Clusters in Large Spatial Databases with Noise. in Proceedings of the 2nd International Conference on Knowledge Discovery and Data Mining 226-231 (1996).

12. Nissen-Meyer, T. et al. AxiSEM: Broadband 3-D seismic wavefields in axisymmetric media. Solid Earth 5, 425-445 (2014).

13. Leng, K., Korenaga, J. \& Nissen-Meyer, T. 3-D scattering of elastic waves by small-scale heterogeneities in the Earth's mantle. Geophys. J. Int. 223, 502-525 (2020).

14. French, S. W. \& Romanowicz, B. A. Whole-mantle radially anisotropic shear velocity structure from spectral-element waveform tomography. Geophys. J. Int. 199, 1303-1327 (2014). 


\section{Figures}
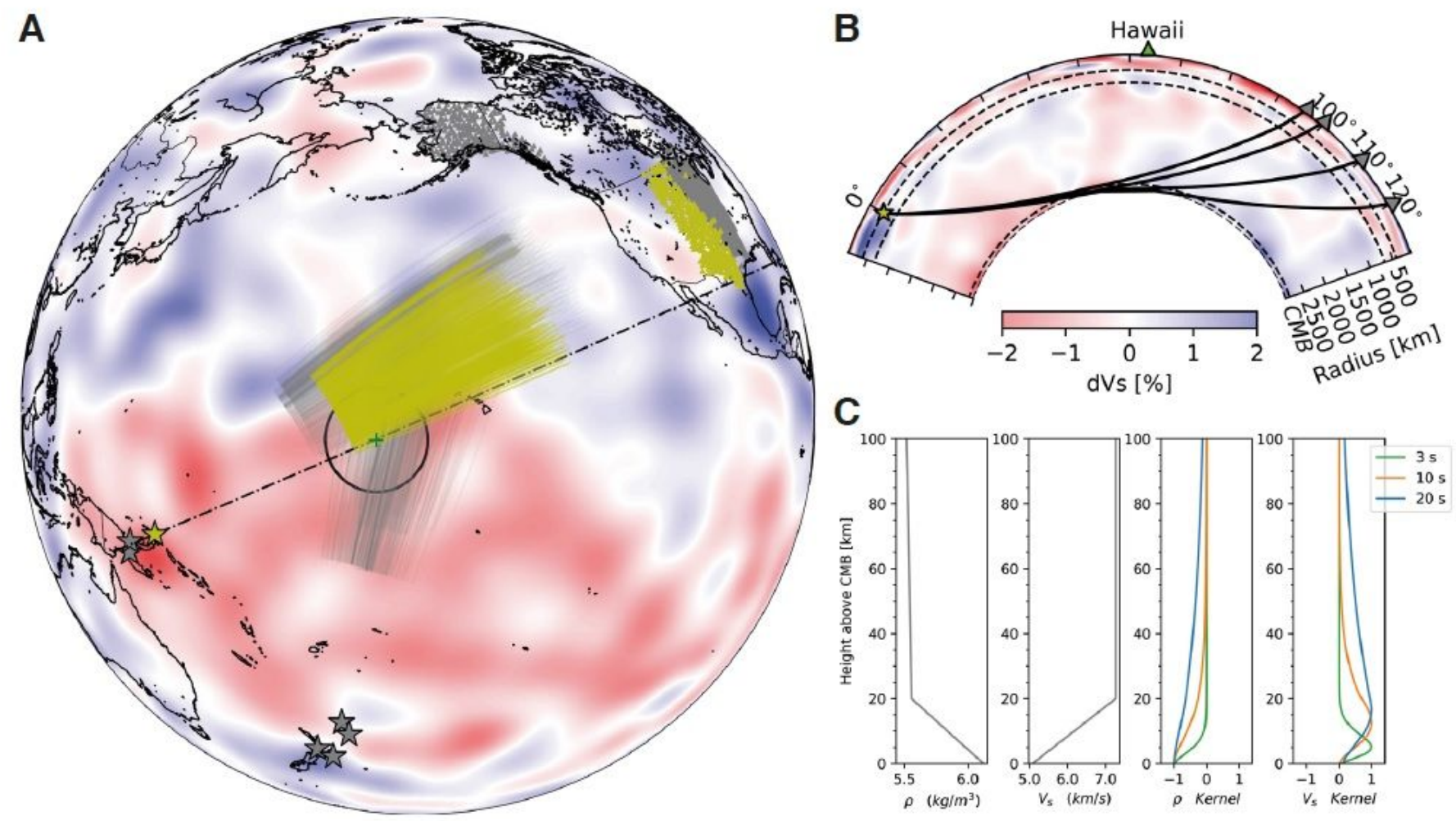

\section{Figure 1}

Sdiff ray paths and sensitivity to velocity structure. (A) Events (stars), stations (triangles), and raypaths of Sdiff waves in the lowermost mantle used in this study, the event used in short-period analysis highlighted in yellow. Proposed ULVZ location shown with black circle. Background shows tomography model SEMUCB_WM1 at $2800 \mathrm{~km}$ depth28. (B) Cross section along the black dashed line in (A) slicing the center of Hawaiian ULVZ, showing raypaths of Sdiff waves at $96^{\circ}, 100^{\circ}, 110^{\circ}$ and $120^{\circ}$. (C) Estimated sensitivity kernels of Sdiff waves for a model containing strongly reduced velocities at the core-mantle boundary. From left to right: density profile, shear wave velocity profile, density kernel, and shear wave kernel for Sdiff waves at period of 3s, 10 s and 30 s. 

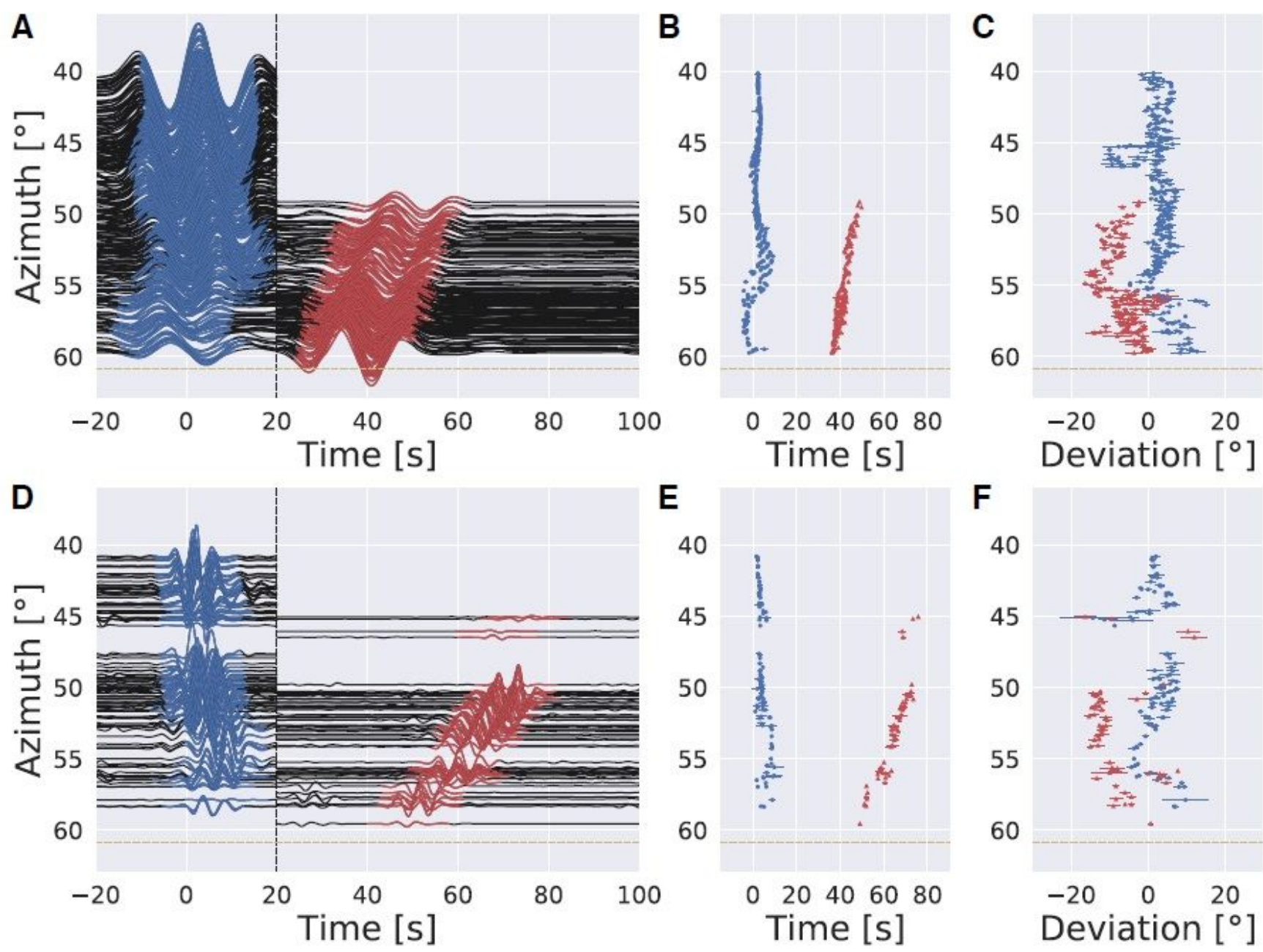

\section{Figure 2}

Stacked data and beamforming results for the main Sdiff phases and postcursors arrivals. (A) Phase weighted stacks for 10-20s filtered data. 300 Data stacks before 20s (black dashed line) use the incoming direction of the main arrival (blue), post 20s stacks use the incoming direction of postcursor energy (red). (B) Travel time measurements from the maxima of stacked waveform envelopes in A. (C) Backazimuth deviations, i.e. the incoming directions used in the stacks. Error bars represent the max variance of the measurement when the value of Sdiff slowness is varied by $\pm 5 \%$. (D-F) as for $A-C$ but for 3-6s filtered data. Yellow dashed lines show the azimuth through the center of the proposed ULVZ 

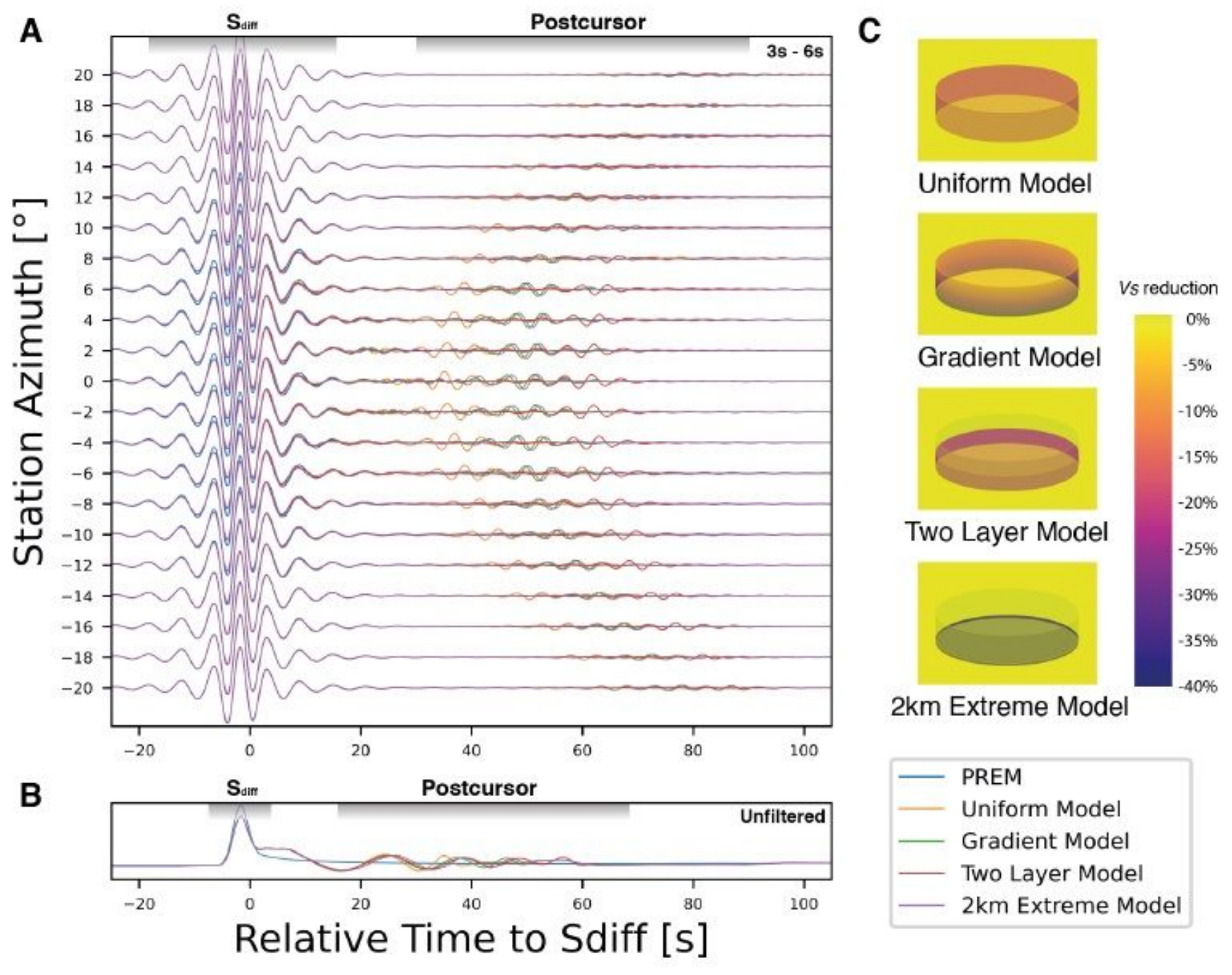

Figure 3

Synthetic global wavefield of four 3D ULVZ models computed to 3s periods. (A) Synthetic waveforms at an epicentral distance of $105^{\circ}$, filtered between $3 \mathrm{~s}-6 \mathrm{~s}$ periods, displayed as a function of azimuth relative to the ULVZ center. (B) Synthetic waveform including all period content down to 3 s period at $0^{\circ}$ relative station azimuth. (C) Illustration of the four different ULVZ models. 


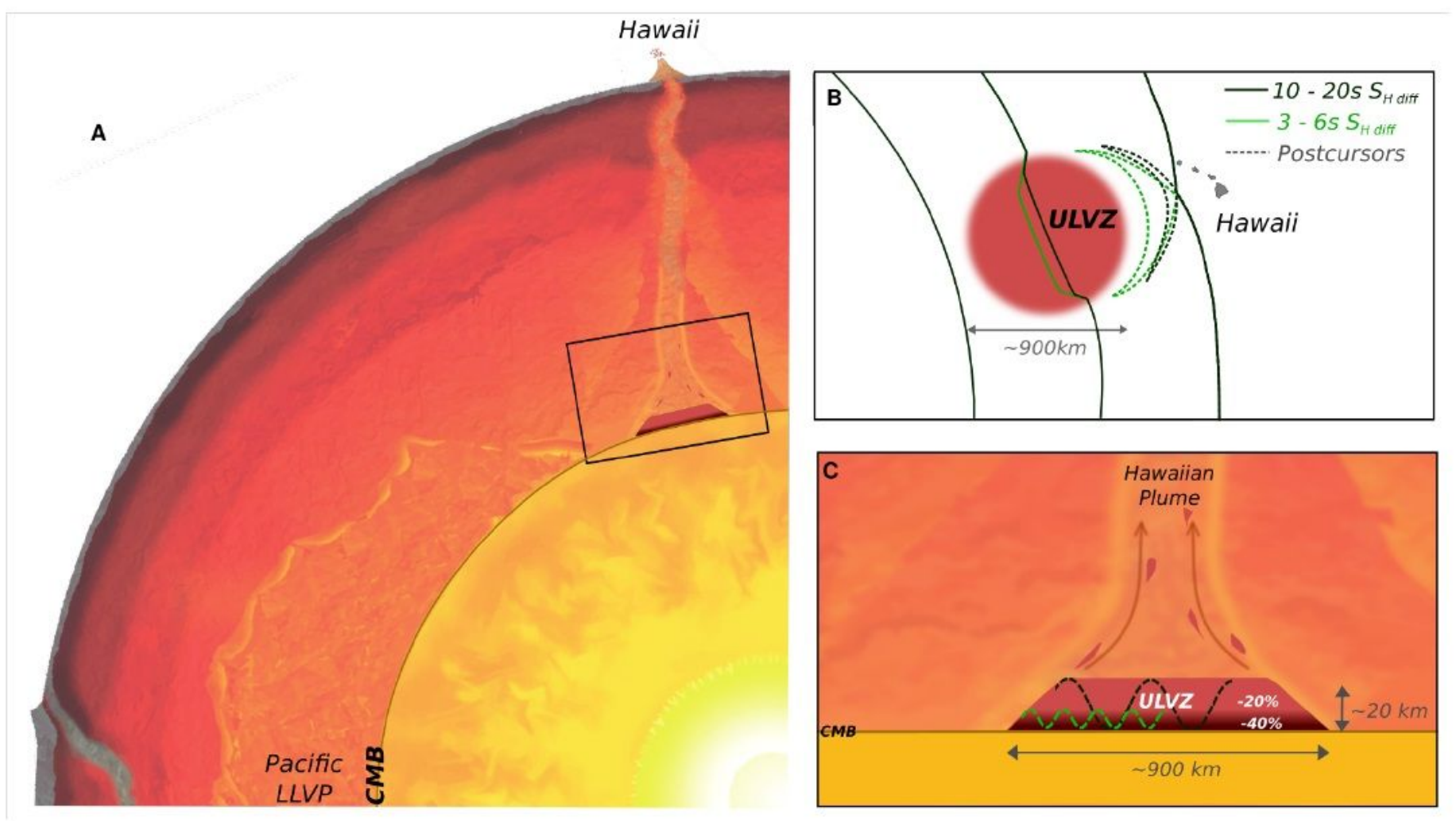

Figure 4

Conceptual cartoons of the Hawaiian ULVZ. (A) ULVZ on the core-mantle boundary at the base of the Hawaiian plume (height is not to scale), (B) sketch of wavefront refraction for the long-period (black) and short-period (green) Sdiff postcursors, and (C) a zoom in of modeled ULVZ structure, showing interpreted trapped postcursor waves (note that the waves analysed have horizontal displacement). 